ISSN: 0212-0267

DOI: http://dx.doi.org/ro.I420I/hedu201837165197

\title{
DEL ECOLOGISMO COMO MOVIMIENTO SOCIAL A LA EDUCACIÓN AMBIENTAL COMO CONSTRUCCIÓN HISTÓRICA
}

\section{From ecologism as a social movement to environmental education as a bistorical construction}

\author{
José Antonio CARIDE \\ Facultade de Ciencias da Educación. Grupo de Investigación en Pedagoxía Social e Educación \\ Ambiental (SEPA-interea). Universidade de Santiago de Compostela \\ Correo-e: joseantonio.caride@usc.es \\ Pablo Ángel Meira \\ Facultade de Ciencias da Educación. Grupo de Investigación en Pedagoxía Social e Educación \\ Ambiental (SEPA-interea). Universidade de Santiago de Compostela \\ Correo-e: pablo.meira@usc.es
}

Recepción: 13 de septiembre de 2017. Envío a informantes: 25 de septiembre de 2017 Aceptación definitiva: is de noviembre de 2017

Resumen: Situando sus argumentos en las convergencias y divergencias que existen entre el «ambientalismo»y el «ecologismo» como movimientos sociales, el texto que presentamos analiza el desarrollo histórico de la Educación Ambiental como una respuesta pedagógica y social a la crisis ambiental en las últimas décadas. Para ello, se parte del concepto de campo social de Pierre Bourdieu y del análisis genealógico de Michel Foucault, desvelando sus significados -simbólicos y materiales- inherentes a los modos de construir el relato institucional, protagonizado fundamentalmente por la UNESCO y el PNUMA, de la Educación Ambiental (EA) y su progresiva sustitución por la que ha dado en llamarse Educación para el DesarroIlo Sostenible (EDS). El afán alternativo y transformador de aquella (EA) se ha ido acomodando a las pretensiones reformistas de esta última (EDS), en un contexto internacional que legitiman los Objetivos del Desarrollo Sostenible, sin que los movimientos ambientalistas, ecologistas y postecologistas estén articulando un plan de acción común, con propuestas educativas compartidas, coherentes y consistentes.

Palabras clave: Educación Ambiental; ecologismo, ambientalismo, postecologismo. 
DEL ECOLOGISMO COMO MOVIMIENTO SOCIAL A LA EDUCACIÓN AMBIENTAL COMO CONSTRUCCIÓN HISTÓRICA

JOSÉ ANTONIO CARIDE Y PABLO ÁNGEL MEIRA

ABSTRACT: The text that we present examines the historical development of Environmental Education as a pedagogical and social response to the environmental crisis of the last few decades, by placing its arguments on the convergences and divergences that exist between «environmentalism» and the «ecologism» as social movements. For this we start from Pierre Bourdieu's concept of social field and Michel Foucault's genealogical analysis, revealing the material and symbolic meanings inherent to the ways of building the institutional story of Environmental Education (EE) and its progressive replacement by that which has become known as Education for Sustainable Development (ESD), which is led mainly by UNESCO and UNEP. The alternative and transforming desire of the former (EA) has been adjusting to the reformist claims of the latter (EDS), in an international context that the Objectives of sustainable development validate, without the environmental movements, ecologists and post-ecologists having to bring together a mutual plan of action, with shared, coherent and consistent educational proposals.

KEY WORDS: Environmental Education, political ecology, environmentalism, post-environmentalism.

\section{Introducción}

$\mathrm{P}$ ONIENDO ÉNFASIS EN LOS SUJETOS ECOLÓGICOS como actores políticos y en la acción ambiental como una práctica contrahegemónica en la esfera pública, la profesora Isabel Carvalho (2002) refiere cómo las condiciones en las que se inscriben los recorridos teórico-prácticos de la Educación Ambiental (en adelante EA) «apuntan hacia un área reciente donde, como en todo cambio ambiental se superponen las marcas de un movimiento social y las de una esfera educativa, epistemológicamente fundamentada e institucionalmente organizada». En ella confluyen adscripciones múltiples y diversas, a las que el pasado -como memoria e historia- desvela profundamente influenciadas por la intención de homogeneizar su campo «por parte de aquellas aproximaciones ligadas al ambiente verde con el foco puesto en la escolarización y en la racionalidad instrumental, por encima de las corrientes críticas y, por ende, mucho más políticas, comprometidas con los complejos problemas socio-ambientales de nuestro tiempo» ${ }^{ }$.

Con demasiada frecuencia, la EA ha quedado subsumida en la normatividad instituida a nivel internacional de relatos y estrategias que van de arriba hacia abajo $^{2}$, que tienden a ocultar y distorsionar las razones profundas de la crisis socioambiental y a sesgar, en consecuencia, sus alternativas para primar las respuestas educativas que no cuestionan los axiomas fundamentales del statu quo

González-Gaudiano, E.: «Educación Ambiental y Educación para el Desarrollo Sustentable ¿tensión o transición?», en GonzÁlez-Gaudiano, E. (coord.): Educación, medio ambiente y sustentabilidad, México, Siglo xxi Editores-Universidad Autónoma de Nuevo León, 2008, pp. 9-24 (c. p. Io).

2 Sauvé, L.; Berryman, T. y Brunelle, R.: «Tres décadas de normatividad internacional para la Educación Ambiental: una crítica hermenéutica del discurso de Naciones Unidas», en GonzálezGaudiano, E. (coord.): op. cit., pp. 25-52. 
DEL ECOLOGISMO COMO MOVIMIENTO SOCIAL A LA EDUCACIÓN AMBIENTAL COMO CONSTRUCCIÓN HISTÓRICA

JOSÉ ANTONIO CARIDE Y PABLO ÁNGEL MEIRA

definido por el mercado y sus coberturas ideológicas liberales y neoliberales. Las divergencias y coincidencias a las que se acude para (con)textualizar su historia en los procesos del ambientalismo/ecologismo y de la participación social en la contemporaneidad ilustran hasta qué punto es preciso adentrarse en lecturas menos condescendientes con su pasado. Y, en relación a él, de lo que podrán ser sus opciones para construir futuros alternativos que, además de acrecentar las resistencias cívicas frente a la vulneración de los derechos sociales y ecológicos, defiendan la vida en toda su diversidad evitando el colapso ecosocial al que está conduciendo nuestro particular modo de vivir y desarrollarnos.

Ante esta tesitura cabe preguntarse: ¿es posible narrar otra historia de la EA?, ¿podemos y/o debemos hacerlo asociando su trayectoria a la de los movimientos sociales de corte ambientalista, ecologista o postecologista? Son dos interrogantes a los que pretendemos dar respuesta con la intención de aportar alguna luz $-\mathrm{O}$, al menos, una luz distinta- a la tarea de desvelar y comprender algunas de las circunstancias que concurren en las respuestas educativas y sociales a la crisis socioambiental, a partir de los años setenta del pasado siglo; más en concreto, desde el momento en que la primera Conferencia Intergubernamental de Educación Ambiental, celebrada en Tbilisi (Georgia) en I977, acostumbra a ser presentada como un hito germinal en la institucionalización de la EA y en su construcción como campo de la praxis socioeducativa.

Lo hacemos proponiendo una aproximación sociohistórica a la EA, a medio camino entre la arqueología foucaultiana y el autosocioanálisis de Bourdieu, distanciándonos con ello del relato histórico más convencional, como el que hicimos tiempo atrás ${ }^{3}$, centrado en los intereses y actuaciones de los organismos internacionales, en buena medida liderados por el binomio que articulan la Organización de las Naciones Unidas para la Ciencia, la Educación y la Cultura (UNESCO) y el Programa de Naciones Unidas para el Medio Ambiente (PNUMA).

Con ello asumimos que es preciso ir más allá de una lectura (auto)crítica de lo que han sido sus posibilidades y limitaciones en las últimas décadas, para aceptar el reto de su reescritura con amplitud de miras: de un lado, la que implica poner en valor el encuentro necesario entre los movimientos sociales y la EA, llegando a considerar que ella misma puede ser interpretada como un movimiento social"; de otro, la que debe permitir superar algunas de las distorsiones que han lastrado y, consecuentemente, afectado a la construcción de la identidad científica, académica y social de la $\mathrm{EA}$, así como a la comprensión y realización práctica de su misión pedagógica y política. Ambos procesos, por acción u omisión, explican el progresivo debilitamiento de la EA como una práctica educativa desleída en los terrenos pantanosos del desarrollo sostenible como marca ambientalista. Aunque también, desde otra perspectiva, como los novísimos movimientos sociales

Véase, principalmente, el capítulo 4 en Caride, J. A. y MeIra, P. Á.: Educación Ambiental y desarrollo bumano, Barcelona, Ariel, 200I, pp. 13I-I88.

4 Esta perspectiva se explora en HerAs, F.: «Los movimientos sociales y la educación ambiental: un encuentro necesario», Aula Verde: Revista de Educación Ambiental, 2I (2000), pp. 3-5, y en Calvo, S. y Gutiérrez, J.: El espejismo de la educación ambiental, Madrid, Morata, 2007. 
DEL ECOLOGISMO COMO MOVIMIENTO SOCIAL A LA EDUCACIÓN AMBIENTAL

COMO CONSTRUCCIÓN HISTÓRICA

JOSÉ ANTONIO CARIDE Y PABLO ÁNGEL MEIRA

herederos del ecologismo del siglo pasado apenas reconocen y utilizan el marco teórico y las herramientas metodológicas de la EA, aunque sus formas de acción político-social den lugar a experiencias de innovación social con una dimensión educativa indudables.

\section{Ambientalismo versus ecologismo, o la necesidad de que las palabras desvelen sus significados}

Iniciándose el siglo xxI, al que muchos -por su coincidencia con la llegada del tercer milenio- saludaron como si se tratase de un verdadero cambio de época, las percepciones y representaciones sociales suscitadas en torno a la crisis ambiental nos han ido situando, en clave histórica, ante dos grandes patrones de racionalización teórica: el ambientalismo y el ecologismo ${ }^{6}$. Ambas voces, que en los diccionarios acostumbran a manejarse como si fuesen homologables, suelen explicarse mutuamente entre sí, siendo lo más habitual que el primero se defina recurriendo al segundo para dar cuenta de sus significados. Es así como el ambientalismo deviene en el ecologismo; y este, tal y como se define en el Diccionario de la Real Academia de la Lengua Española, en un movimiento sociopolítico que propugna la defensa de la naturaleza y la preservación del medio ambiente.

Esta última expresión -junta o separada, ya que se admiten indistintamenteacabará reduciéndose al «medio», concebido como un conjunto de circunstancias exteriores a un ser vivo. Tales «circunstancias» no siempre encuentran en las palabras los mejores modos de mostrar quiénes somos ni las realidades a las que aluden, transitando entre la retórica y el vacío, la indolencia y la vehemencia en la que suelen incurrir los usos y abusos a los que son sometidos estos términos en la actualidad: una realidad susceptible de indagación científica, un tema de discusión, un bien a preservar, una especulación o un escenario -natural y/o artificialen el que se desarrollan biológica y socialmente las personas, poniendo énfasis en las relaciones que establecen con los demás seres vivos ${ }^{7}$. Este enfoque ha ido evolucionando hacia nociones más holísticas y ecosistémicas, aunque persista la utilización indiscriminada de los vocablos medio, ambiente, medio ambiente, etc.

Se avanzará, en pocas décadas aunque con resistencias y dificultades, hacia una progresiva convergencia disciplinar de las Ciencias Naturales y Ambientales con las Ciencias Sociales, aportando lecturas del mundo desconocidas hasta los primeros años del siglo xix. Es entonces cuando la Ecología Humana incorpora un enfoque sociológico, diferenciado temática y metodológicamente de la Ecología general ${ }^{8}$, que se pretende que sea compatible con la declarada vocación

Pardellas, M.; Meira, P. Á. y Iglesias, L.: «Transition communities and the glass ceiling of environmental sustainability policies at three universities», International Journal of Sustainability in Higher Education, I8, 4 (2017), pp. 576-593.

6 Caride, J. A. y Meira, P. Á.: op. cit.

George, P.: L'environnement, París, Puf, I97I.

8 En este cambio de enfoque fueron pioneras las obras de Amos H. Hawley: Ecología humana, Madrid, Tecnos, 1962, y Teoría de la ecología humana, Madrid, Tecnos, I991. 
DEL ECOLOGISMO COMO MOVIMIENTO SOCIAL A LA EDUCACIÓN AMBIENTAL COMO CONSTRUCCIÓN HISTÓRICA

JOSÉ ANTONIO CARIDE Y PABLO ÁNGEL MEIRA

interdisciplinar integradora y unificadora del conocimiento que abraza el desafío ecológico ${ }^{9}$. Una perspectiva que acentuará el ecologismo ${ }^{\mathrm{ro}}$, al modificarse -conceptual, ideológica y normativamente- la visión existente sobre los ecosistemas; $y$, con ella, sobre las redes que tejen los seres humanos con la naturaleza y la técnica, la economía y la política. Desde los años setenta, tras la celebración -en 1972- de la Conferencia Mundial sobre Medio Ambiente Humano en Estocolmo, la protección del medio ambiente forma parte de las agendas impulsadas por los gobiernos y los organismos internacionales (Naciones Unidas, Unión Europea, etc.); también de la iniciativa cívica, comenzando a ser estudiada por los analistas de las políticas públicas y de las dinámicas sociales, procurando cultivar una mayor información y formación ciudadana, así como en la toma de decisiones, actuando para buscar soluciones -incluyendo un cambio de valoresque permitan afrontar la crisis socioambiental.

Según Prades ${ }^{\mathrm{II}}$, esta «apertura» se asocia a tres miradas distintas y, al tiempo, complementarias: la empírica, que habla de un fenómeno múltiple, heterogéneo y polifacético, que incluye su consideración como un movimiento social; la tipológica, en la que incluye la «ecología profunda», el «ecodesarrollo» y el «economismo puro»; y la teórica, que, además de invitar a una actualización de la obra de los clásicos de la Sociología, sugiere nuevas pistas de análisis sobre la influencia que ha ejercido el espíritu capitalista en la transformación de un mundo que pasa de agrícola y tradicional a industrial y moderno, con sus últimas variantes en el proceso de globalización. Para $\mathrm{Naredo}^{12}$, la temática ambiental-ecológica ganará terreno en el mundo académico, en las instancias político-administrativas y en los medios de comunicación social, siendo concordante esta dinámica con una mayor sensibilidad de la población. Y, con ellas, la visibilidad de los desajustes entre el crecimiento económico, con los modelos de desarrollo que lo estimulan, y los límites físicos del planeta.

Más allá de sus connotaciones semánticas, ambientalismo y ecologismo han proyectado sus inquietudes sociales en líneas de pensamiento, reflexión y acción divergentes, con argumentos ideológicos, socioeconómicos, culturales y éticamente plurales e, incluso, en algunos casos prácticamente irreconciliables. De un lado, porque los movimientos sociales y las indagaciones intelectuales que se han ido construyendo en torno a ellos no han podido eludir las palabras que los identifican, posicionándose a favor o en contra de sus respectivos enfoques; de otro, porque -como una toma de postura más- suele evitarse entrar en las diferenciaciones que existen entre ambientalistas y ecologistas, como si el establecimiento de un «a priori» que justifique esta inhibición permita aludir, sin matices, a «un» movimiento social que se ocupa y preocupa por la defensa del medio

9 Goldsmith, E.: The Way: an Ecological World-View, Londres, Rider, 1992.

ro Simonnet, D.: L'écologisme, París, Presses Universitaires de France, 1979.

i Prades, J. A.: «Ecologismo», en Giner, S.; Lamo de Espinosa, E. y Torres, C. (eds.): Diccionario de Sociología, Madrid, Alianza Editorial, I998, p. 223.

${ }_{12}$ Naredo, J. M.: Raíces económicas del deterioro ecológico y social: más allá de los dogmas, Madrid, Siglo XxI Editores, 2006. 
ambiente $^{13}$, cuando en realidad existe un abanico variado de agentes políticos y sociales que buscan alternativas para enfrentar el desequilibrio global, agudizado por la indolencia de los poderes instituidos, que obstaculizan los cambios sociales y acentúan las desigualdades al no aportar o demorar las soluciones que deben adoptarse ante los problemas urgentes ${ }^{14}$.

En todo caso, como señalara la profesora Yayo Herrero' ${ }^{15}$, sus dinámicas confluyen en la sensibilización que surge con las reiteradas advertencias sobre los riesgos -ecológicos y/o ambientales- inherentes a un deterioro global del planeta, impactando de lleno en las comunidades humanas: «La crisis ambiental y los temas ecológicos -dirá- fueron empapando los ámbitos académicos, sociales y políticos, obligando a que instituciones y agentes sociales de todo tipo incluyesen en sus discursos y líneas directrices la problemática ambiental $\aleph^{16}$. Aunque alude, posteriormente, a lo que denomina «movimiento ecologista», advierte como en realidad se trata de «un movimiento plural, que recoge los planteamientos de las opciones más puramente conservacionistas (que centraban su actividad en la conservación de especies o espacios naturales), las luchas enmarcadas dentro de la ecología política (que incorporan la dimensión económica en los análisis ecológicos), las reivindicaciones ecofeministas, posicionamientos en los conflictos ecológico-distributivos y, en muchos casos, todos ellos a la vez» ${ }^{17}$.

Sin embargo, históricamente las respuestas sociales a la crisis ecológica/ambiental y sus impactos en nuestros ecosistemas no se explican únicamente en función de las tensiones provocadas por los modelos de desarrollo adoptados -entre el crecimiento ilimitado y la pretendida sostenibilidad- y su afán por satisfacer las necesidades humanas salvaguardando la biodiversidad. De ahí la importancia de no confundir entre los modos a través de los que tales necesidades pueden ser satisfechas y las formas de hacerlo. Máxime cuando se sigue constatando que el uso y abuso de los recursos naturales, incrementando las enormes desigualdades sociales existentes, hace que la producción sea un fin en sí mismo.

A pesar del sustrato común que los vincula, la «reforma ambientalista» está lejos de poder equipararse al «cambio ecologista $»^{18}$. Como ya hemos analizado tiempo atrás ${ }^{19}$, por mucho que partan e, incluso, compartan la necesidad imprescindible y

13 Martín, F.: «Contribuciones para el estudio de los movimientos sociales en defensa del medio ambiente», Apuntes de Investigación del CECYP, 27 (2016), pp. 219-232.

${ }_{14}$ Fisher, J.: El camino desde Río: el desarrollo sustentable y el movimiento no gubernamental en el Tercer Mundo, México, Fondo de Cultura Económica, I993.

is Herrero, Y.: «El movimiento ecologista ante el deterioro global: retos y utopías», Intervención Psicosocial, I5, 2 (2006), pp. I49-166.

${ }_{16}$ Ibidem, p. 154.

${ }^{17}$ Ibidem, p. 155 .

18 Para profundizar en la definición ideológica y política del ecologismo y en su evolución recomendamos acudir a GoRz, A.: Capitalismo, socialismo, ecología, Madrid, Editorial HOAC, I995; Dobson, A.: Pensamiento político verde. Una nueva ideología para el Siglo XXI, Barcelona, Paidós, 1997; y LefF, E.: «Las relaciones de poder del conocimiento en el campo de la ecología política», Ambiente E Sociedade, 20, 2 (2017), pp. 229-262.

19 Nos referimos al capítulo 2 en Caride, J. A. y Meira, P. Á.: op. cit., pp. 67-94. 
DEL ECOLOGISMO COMO MOVIMIENTO SOCIAL A LA EDUCACIÓN AMBIENTAL COMO CONSTRUCCIÓN HISTÓRICA

JOSÉ ANTONIO CARIDE Y PABLO ÁNGEL MEIRA

urgente de articular respuestas que eviten el deterioro de sistemas vitales básicos, cuestionando su ordenación antropocéntrica, existen diferencias relevantes entre las perspectivas ambientalista y ecologista: en la primera, en la que se incluyen el proteccionismo conservacionista y el enfoque del desarrollo sostenible, no se plantea una alternativa global, al preocuparse fundamentalmente por mejorar las acciones de los seres humanos sobre la naturaleza para conservarla y para que sea económicamente productiva; mientras que en la segunda -invocando el ecosocialismo, la ecología política o la ecología popular-se consideran inevitables cambios radicales en nuestras formas de vida social y política, en la economía y sus estilos de desarrollo, producción y consumo, el poder de los mercados y de los soportes ideológicos que les brinda el sistema capitalista. Como dirían, en clave pedagógica, Colom y Mèlich, «el ambientalismo se diferencia fundamentalmente del ecologismo porque no contempla las transformaciones sociales, políticas y económicas que... se integran en la postura ecologista ${ }^{20}$.

Frente a las imprecisiones e inconsistencias de los posicionamientos ambientalistas -sobre todo al tratar de conciliar el desarrollo capitalista con la sostenibilidad, la tecnología con la preservación ambiental-, las opciones ecologistas -con mayor o menor radicalidad- han puesto de relieve cómo el modelo neoliberal de mercado, lejos de configurarse como un marco idóneo para superar la crisis socioambiental, es reincidente en aspectos que cuestionan la racionalidad que lo fundamenta, ocultando los síntomas de un sistema socioeconómico ética y políticamente agotado, porque es incapaz de satisfacer las necesidades básicas de toda la población; inductor de rupturas y desequilibrios demográficos; generador de daños ambientales y en la salud humana; destructor de los recursos renovables y no renovables; instigador de nuevas violencias e inseguridades; etc. En los primeros años del siglo xxI, el cuidado del planeta y los impactos que sobre la «salud ambiental» tiene el cambio climático se han convertido en un laboratorio político, social y psicológico de primer orden, entre la ética y la pragmática, lo importante y lo urgente ${ }^{21}$, ya sea en el ámbito de las políticas públicas (locales, nacionales, supranacionales) o en el de los movimientos cívicos. En realidad, de ambos... sin que podamos resolver la incongruencia que implica llamar de modo diferente-ambientalismo versus ecologismo-a lo que suele presentarse terminológicamente como lo mismo.

\section{Ecologismo y ambientalismo como movimientos sociales alternativos}

El sistema económico, con la complicidad de las estructuras de poder, sigue alentando la competencia por los beneficios, ampliando los mercados y su apego a un consumo insaciable. La resistencia a abandonar el paradigma del crecimiento económico, abonado por las tesis del capitalismo neoliberal, complica

20 Colom, A. J. y MèLich, J.-C.: Después de la modernidad. Nuevas filosofías de la educación, Barcelona, Paidós, 1994, pp. 176-177.

${ }^{21}$ Sampedro, J.: artículo citado. 
sobremanera la adopción de alternativas que trasciendan los debates ambientales y las soluciones basadas en las innovaciones tecnológicas, para centrarse en sus aspectos sociales y éticos ${ }^{22}$ : de justicia socioambiental entre poblaciones, siendo plenamente conscientes de que afecta no solo a los derechos y deberes contraídos con las generaciones del presente, sino también con las que habiten el futuro.

Desde la difusión en 1987 del Informe coordinado por Gro Harlem Brundtland con el título Nuestro futuro común², lo que se ha dado en llamar «desarrollo sostenible» parece sintetizar sus aspiraciones, a pesar de la calculada vaguedad del término y las controversias que encierra. Lo sostenible y/o la sustentabilidad en el desarrollo, que tiene su origen en los trabajos previos a la Cumbre de la Tierra, celebrada en Río en 1992, legitimando su estatus en la que se celebró en Johannesburgo diez años después, no puede substraerse de ser visto como «una estrategia interna para institucionalizar la ambigüedad, los discursos y los movimientos de protesta social» ${ }^{24}$. Con su formulación se diluye el trabajo de sensibilización, concienciación y denuncia que venían dinamizando los movimientos sociales proambientales en los últimos decenios. Y, si bien es cierto «que nos ha dado la oportunidad para debatir y disputar sobre un terreno de juego común... [no lo es menos] que nos ha llevado a disfrazar con el mismo traje intereses y visiones históricamente confrontadas $»^{25}$.

En este escenario, al igual que sucede con todos los movimientos sociales -una expresión que se aplica a una variada gama de procesos colectivos orientados a producir cambios en las instituciones y el orden social existente-, convencionales o alternativos, todo indica que la voluntad democrática a la que remiten sus sentimientos de pertenencia no puede hacerse desde la homogeneidad, sino más bien desde la heterogeneidad y la pluralidad inherente -en las ideas y en los hechos-a sus propuestas de cambio, sean de alcance local y/o global, desbordando las vagas connotaciones de lo que se ha dado en llamar sociedad civil ${ }^{26}$. De ahí que, invocando la diversidad como un principio consubstancial para el logro de mayores cotas de equidad y justicia social, los movimientos cívicos contemporáneos propongan superar el concepto unívoco de utopía, abriendo sus significados hacia una ciudadanía multicultural, cosmopolita y planetaria ${ }^{27}$.

22 RocA, J.: op. cit.

23 Comisión Mundial de Medio Ambiente y Desarrollo: op. cit.

${ }^{24}$ Gutiérrez, J. y Pozo, M. T.: «Stultifera Navis: celebración insostenible», en GonzÁLezGaudiano, E. (coord.): op. cit., p. 97.

${ }_{25}$ Ibidem.

${ }_{26}$ Véanse, al respecto, Edwards, M.: Civil Society, Cambridge, Polity Press, 2004; Hall, J. A.: «In Search of Civil Society», en Hall, J. A. (ed.): Civil Society: Theory, History, Comparison, Cambridge, Polity Press, 995 pp. I-3I, 1995; Giner, S.: «Sociedad civil», en Enciclopedia Iberoamericana de Filosofía, vol. io (Filosofía Política, II), Madrid, csic-Trotta, I996, pp. II7-I46; IbARrA, P.: Manual de sociedad civil y movimientos sociales, Madrid, Síntesis, 2005; KEAnE, J.: Democracia y sociedad civil, Madrid, Alianza, I992; y LarañA, E. y Gusfield, J. (eds.): Los nuevos movimientos sociales: de la ideología a la identidad, Madrid, Centro de Investigaciones Sociológicas, I994.

${ }_{27}$ Sposati, A.: «Movimentos utópicos da contemporaneidade», en Sorrentino, M. (coord.): Ambientalismo e participação na contemporaneidade, São Paulo, Educ/FAPESP, 2002, pp. IO-39. 
DEL ECOLOGISMO COMO MOVIMIENTO SOCIAL A LA EDUCACIÓN AMBIENTAL COMO CONSTRUCCIÓN HISTÓRICA JOSÉ ANTONIO CARIDE Y PABLO ÁNGEL MEIRA

No se puede obviar, como señala Laraña ${ }^{28}$, que la proliferación de estos movimientos está relacionada con la crisis de credibilidad de los cauces tradicionales de participación en las democracias occidentales, que afecta especialmente al sistema de partidos políticos y motiva la búsqueda de formas alternativas de participación, más directas y próximas a las realidades cotidianas de los individuos. Una expectativa en la que abundan quienes sitúan la esperanza de dotar a la humanidad de un verdadero proceso de emancipación civilizatoria, superadora de la dicotomía individuo-sociedad, así como de los valores, actitudes y comportamientos heredados en las relaciones con la naturaleza ${ }^{29}$.

Muchos de los malestares que se producen en los territorios fronterizos de la bios y la polis, del ego y el socius, de la tradición y el cambio..., con un trasfondo ecológico y/o ambiental, se proyectan en los «nuevos» movimientos sociales dotándolos de un elemento identitario diferencial, ampliando o complementando las «viejas» reivindicaciones de los movimientos sindicales y populares de clase, articulados predominantemente en su lucha contra las desigualdades sociales inducidas por el liberalismo económico y el modelo de producción capitalista.

Lo «ambiental» y lo «ecológico», junto con las cuestiones de género y la orientación sexual -y, en ocasiones, la emancipación de los pueblos y la construcción de una cultura de paz-, serán los principales referentes de un quehacer colectivo en el que tendrán un especial protagonismo las concepciones antropocéntricas versus ecocéntricas que vertebran el pensamiento ecologista-ambientalista desde hace varias décadas ${ }^{3 \circ}, \mathrm{y}$, con ellas, las particulares visiones que ofrecen sobre los vínculos sociedad-naturaleza. El cruce de sus miradas, entre lo ideal y lo material, ha cristalizado en el quehacer cívico de los movimientos sociales aportándoles señas de identidad de nuevo cuño, en las que el anhelo por democratizar la democracia, como diría Boaventura de Sousa Santos ${ }^{31}$, no se puede separar de las críticas a los modelos tradicionales de participación social y a la cultura política que los ampara, esbozando la exigencia de que la movilización ciudadana sea, en sí y por sí misma, un modo de activar las alternativas de sociedad en el orden global ${ }^{32}$.

28 Laraña, E.: La construcción de los movimientos sociales, Madrid, Alianza Editorial, 1999.

29 Elias, N.: El proceso de la civilización (investigaciones sociogenéticas y psicogenéticas), México, Fondo de Cultura Económica, 1987.

30 Foladori, G.: «El pensamiento ambientalista», Tópicos en Educación Ambiental, 2, 5 (2000), pp. 2I-38.

${ }_{31}$ Santos, B. de S.: Democratizar a democracia: os caminhos da democracia participativa, Lisboa, Fundación Gulbenkian, 20oI.

32 La aparición de los «nuevos» movimientos sociales en los años setenta y ochenta del siglo pasado abrió un debate sobre su potencial para redefinir las prácticas democráticas ligadas a los sistemas representativos de partidos tradicionales. Véase Dalton, R. J. y Kuechler, M.: Los nuevos movimientos sociales: un reto al orden político, Valencia, Editorial Alfons el Magnàmim, I992; RodRíGUEZ Villasante, T.: Las democracias participativas: de la participación ciudadana a las alternativas de sociedad, Madrid, Ediciones HOAC, I995; TARROw, S.: El poder en movimiento: los movimientos sociales, la acción colectiva y la política, Madrid, Alianza, 1996; Held, D.: La democracia y el orden global: del Estado moderno al gobierno cosmopolita, Barcelona, Paidós, I997; IBARRa, P. y Tejerina, B. (eds.): Los movimientos sociales: transformaciones políticas y cambio cultural, Madrid, Trotta, 1998. 
DEL ECOLOGISMO COMO MOVIMIENTO SOCIAL A LA EDUCACIÓN AMBIENTAL COMO CONSTRUCCIÓN HISTÓRICA

JOSÉ ANTONIO CARIDE Y PABLO ÁNGEL MEIRA

Es entonces cuando la expresión «nuevos» movimientos sociales o movimientos sociales alternativos concentra sus luchas en torno al feminismo, el ecologismo y el pacifismo. Un movimiento de movimientos que llega al presente encarnándose en las luchas contra la globalización. Esta evolución no supone la desaparición de las tendencias y las diferencias ideológicas, tácticas y estrategias de quienes confluyen en esta red de redes ${ }^{33}$, en la que concurren sindicatos y partidos políticos de izquierda, organizaciones ecologistas, pacifistas y feministas, etc., que ponen el acento en la defensa de los derechos humanos, civiles y sociales. La tentación de oponer sociedad y Estado, dirá Arditi ${ }^{34}$, acabará determinando que la política comience «a parecerse cada vez más a un archipiélago de circuitos, uno que aquí hemos denominado post-liberal porque excede los parámetros de la política tal y como fue pensada por el liberalismo democrático clásico».

No obstante, más allá de estas consideraciones y ante la crisis global, el reto del movimiento ecologista en el presente es múltiple, por lo que no puede diluirse, sino reforzarse con las sinergias de otros movimientos sociales, si en verdad se pretende transitar hacia un mundo que sea justo y sostenible ${ }^{35}$. Un reto que tampoco puede eludir la redefinición de su propia identidad y su misión social ante la aparición de neomovimientos que se originan en el campo del ecologismo gestado en el siglo xx, pero que asumen la inexorabilidad del colapso ecológico dada la imposibilidad de parar el choque de la humanidad con los límites biofísicos del planeta; movimientos postecologistas o postdesarrollo (transitión towns, decrecentistas, permaculturalistas, etc.) que tienen en común descontar cualquier posibilidad de cambio dentro de la sociedad de mercado y se preparan para el postcolapso, como más adelante comentaremos.

Ese reto es urgente, ante la gran encrucijada que se abate sobre la humanidad en lo que puede interpretarse como un cambio de ciclo histórico, en el que desempeñan un papel clave las transiciones globales con estrategias para afrontar la posibilidad del colapso provocado por el desbordamiento de los límites biofísicos del planeta ${ }^{36}$. Una crisis ecosocial para la que sugieren, entre otras, estrategias que permitan una reapropiación democrática del marco político, a través de un proceso constituyente que incorpore los retos ecológicos; la preservación de los ecosistemas que sustentan la vida, recuperando y generando resiliencia en los ecosistemas naturales; afrontar urgentemente el cambio energético/climático, yendo hacia una sociedad descarbonizada y resiliente; reformular las lógicas económicas, dotándonos de un marco socioeconómico más democrático, justo

33 Riechmann, J. y Fernández Buey, F.: Redes que dan libertad: introducción a los movimientos sociales, Barcelona, Paidós, 2000 (3. ${ }^{\mathrm{a}}$ ed.).

${ }_{34}$ Arditi, B. (ed.): ¿Democracia post-liberal? El espacio político de las asociaciones, Barcelona, Anthropos, 2005, pp. I2-I3.

35 Véase Herrero, Y.: «Miradas ecofeministas para transitar a un mundo justo y sostenible», Revista de Economía Crítica, i6 (2013), pp. 40-65, y Herrero, Y.; Cembranos, F. y Pascual, M. (coords.): Cambiar las gafas para mirar el mundo: hacia una cultura de la sostenibilidad, Madrid, Libros en Acción, 20II.

${ }_{36}$ Prats, F.; Herrero, Y. y Torrego, A.: La gran encrucijada: sobre la crisis ecosocial y el cambio de ciclo histórico, Madrid, Libros en Acción, 20I6, pp. III-I32. 
DEL ECOLOGISMO COMO MOVIMIENTO SOCIAL A LA EDUCACIÓN AMBIENTAL COMO CONSTRUCCIÓN HISTÓRICA

JOSÉ ANTONIO CARIDE Y PABLO ÁNGEL MEIRA

y sostenible; redefinir las estrategias territoriales y urbanas, afrontar el cambio cultural, renovando la formación, la cultura y las actuaciones científico-técnicas.

En el interior de estas y otras opciones, ha procurado la educación -en ocasiones adjetivada como ambiental; en otras, como ecológica; $y$, en los últimos años para el desarrollo sostenible- acomodar sus argumentos, trenzando una compleja malla de interacciones pedagógicas y sociales, sin eludir las controversias que sus respectivos posicionamientos han generado en la esfera pública ${ }^{37}$ y, por lo tanto, también en el tejido social y en la política como estilo de vida. Para Isabel Carvalho, además de poner de manifiesto las vicisitudes que subyacen a la crisis de la modernidad, el «giro cultural de los nuevos movimientos sociales transclasistas y la nueva izquierda, es una transformación importante en la cultura política con fuerte expresión en el mundo ambiental» ${ }^{8}$. Pensada de esta forma, la cuestión ecológica y/o ambiental desvela sus posicionamientos como un «hecho» histórico, cuyo encuadre diacrónico y sincrónico evoca la necesidad de armonizar distintas interpretaciones de la realidad y de sus problemas asociados, en clave ideológica, ética, científica, económica, política, pedagógica y social.

\section{La re-deconstrucción histórica de la Educación Ambiental en la lógica de los «movimientos» pedagógicos y sociales}

De acuerdo con lo que hemos anticipado, recurriremos a dos autores -Pierre Bourdieu y Michel Foucault- que nos sitúan ante un cometido intelectualmente paradójico y, en algunas de sus derivaciones, tan impredecible como improbable. El primero, que se autodefinía como "estructuralista constructivista» ${ }^{39}$, jugando conscientemente con un oxímoron, arrastra una infundada etiqueta de determinista, sobre todo en el campo educativo y entre quienes no han leído más allá de Los Herederos o La Reproducción, sus obras sobre el campo educativo más ortodoxamente estructuralistas. De su pensamiento interesa aquí su posición crítica, el socioanálisis, y la noción de campo social aplicada topológicamente a la EA, entendida ella misma como un improbable campo en proceso de construccióndeconstrucción ${ }^{40}$; o, jugando con el concepto acuñado por Bourdieu, como un trans-campo en el que se superponen dos campos que obedecen a lógicas y posiciones sociales distintas: el educativo, por una parte, $\mathrm{y}$ el ambiental, por otra ${ }^{4+}$.

37 Scheres-Warren, I.: Cidadania sem fronteiras: ações coletivas na era da globalização, São Paulo, Hucitec, I999.

${ }^{38}$ Carvalho, I. C. M.: «El sujeto ecológico y la acción ambiental en la esfera pública: una política en transición y las transiciones en la política», Tópicos en Educación Ambiental, 4, Io (2002), pp. 37-49 (c. p. 38).

39 Bourdieu, P.: Cosas dichas, Buenos Aires, Gedisa, 1988, p. I27.

40 Derrida, J.: Cómo no hablar y otros textos, Barcelona, Anthropos, 1989.

${ }_{41}$ Sobre el desarrollo del concepto de «trans-campo» aplicado al análisis del ámbito de la EA pueden consultarse Barba, M.: A educación ambiental en Galicia. Análise socio-biográfica da súa construción como campo, tesis doctoral, Santiago de Compostela, Universidade de Santiago de Compostela, 20I6; y Barba, M.; Morán, M. C. y Meira, P. Á.: «La educación ambiental en tiempos de crisis. ¿Dónde está cuando más se necesita?», Ambiente E Sociedade, xx, 3 (2017), pp. 139-I58. 
DEL ECOLOGISMO COMO MOVIMIENTO SOCIAL A LA EDUCACIÓN AMBIENTAL COMO CONSTRUCCIÓN HISTÓRICA

JOSÉ ANTONIO CARIDE Y PABLO ÁNGEL MEIRA

Como campo o trans-campo, está sometido a tensiones difícilmente perceptibles por quienes lo habitamos y que, quizás, puedan desvelarse a la luz del socioanálisis histórico. La finalidad es, en este sentido, revisar algunas «piezas» de la trayectoria histórica de la EA para intentar ir más allá de una visión lineal, descontextualizada y plana, sin sujetos y sin apenas conflictos, que se desprende del itinerario institucional que se suele trazar desde principios de los años setenta hasta la actualidad. Una evolución que, arbitrariamente, suele partir de la Conferencia de Estocolmo (1972) y acabar con la últimas celebraciones consagradas por el sistema de las Naciones Unidas, hoy por hoy, materializadas en el $4 .{ }^{\circ}$ Congreso Internacional sobre Educación Ambiental Tbilisi+3o, celebrado en Ahmedabad (India), en noviembre de 2007 y, más recientemente, en la incorporación de la Educación para el Desarrollo Sostenible (en adelante, EDs) en los Objetivos del Desarrollo Sostenible establecidos por la ONU en 2015.

El uso de la noción de campo como concepto analítico para explorar la Educación Ambiental no es original. A ella han recurrido autores y autoras como Carvalho ${ }^{42}$, González-Gaudiano ${ }^{43}$, De Alba ${ }^{44}$, Meira $^{45}$ o Barba ${ }^{46}$. De Bourdieu también interesa cómo acota el papel del «intelectual crítico» ante los retos de la sociedad contemporánea. Su concepción puede servir para reforzar y reconstituir un rol menos ingenuo y más efectivo de quienes hacen desde su labor investigadora y formativa un esfuerzo por comprender e impulsar el papel de la educación en el seno de los movimientos ecologistas y sus respuestas a la crisis socioambiental. Bourdieu define el «intelectual crítico» como «alguien que compromete en un combate político su competencia y su autoridad específicas, y los valores asociados al ejercicio de su profesión, como valores de verdad o desinterés, o, dicho de otra forma, alguien que pisa el terreno de la política pero sin abandonar sus exigencias y sus competencias de investigador» ${ }^{47}$. Con este perfil, el sociólogo francés invita a rechazar el intelectualismo academicista y a dejar de considerar las revoluciones en el orden de los conceptos o de los textos como revoluciones en el orden de las cosas, tal y como está sucediendo, por ejemplo, con la substitución del discurso de la EA por el de la Educación para el Desarrollo Sostenible (EDs), que ha recibido su último refrendo institucional con los Objetivos del Desarrollo Sostenible (2015-2030) por parte de las Naciones Unidas. Lo mismo que también es preciso reconocer que «las palabras hacen las cosas, en gran parte, y

42 Carvalho, I. C. M.: A Invenção Ecológica. Narrativas e Trajetórias da Educação Ambiental no Brasil, Porto Alegre, Universidade Federal de Rio Grande do Sul, 2oor.

${ }^{43}$ González-Gaudiano, E.: Educación Ambiental: trayectorias, rasgos y escenarios, México, Plaza y Valdés, 2007.

${ }_{44}$ Alba, A. de: «Investigación en educación ambiental en América Latina y el Caribe. Doce tesis sobre su constitución», en González-Gaudiano, E. (coord.): La educación frente al desafío ambiental global. Una visión latinoamericana, México, CREFAL-Plaza y Valdés, 2007, pp. 277-287.

45 Meira, P. Á.: «Outra lectura da historia da Educación Ambiental e algún apuntamento sobre a crise do presente», Ambientalmente Sustentable, 8 (2009), pp. I6-43.

46 BARba, M.: op. cit.

47 Bourdieu, P.: Contrafuegos 2. Por un movimiento social europeo, Barcelona, Anagrama, 200I, p. 38 . 
DEL ECOLOGISMO COMO MOVIMIENTO SOCIAL A LA EDUCACIÓN AMBIENTAL COMO CONSTRUCCIÓN HISTÓRICA

JOSÉ ANTONIO CARIDE Y PABLO ÁNGEL MEIRA

que cambiar las palabras, y, más generalmente, las representaciones, es ya cambiar las cosas» ${ }^{8}$.

La perspectiva analítica de Foucault, y, fundamentalmente, su enfoque arqueológico y genealógico aplicado al microanálisis del pensamiento social, es la segunda pieza analítica del puzle de la trayectoria de la EA que se pretende recomponer. Su acercamiento a la realidad y a su representación a través de los discursos complementa desde el punto de vista posestructuralista la perspectiva adoptada por Bourdieu. Si este autor permite abordar la construcción -o reconstruccióndel campo y su dinámica social e histórica, tanto interna como externa, la visión arqueogenealógica de Foucault remite a la génesis del discurso -o de los discursos- de la EA; génesis que ha ido marcando los contornos teóricos, históricos y culturales del mismo campo a través de las complejas y herméticas relaciones entre instituciones (nos centramos, en este caso, en el binomio UNESCO-PNUMA), de los discursos que se concretan en las declaraciones oficiales y de las formas de ideología y poder que atraviesa la institucionalización de las respuestas educativas a la crisis ambiental y que tiene su último, y largo capítulo, en la dialéctica entre EA y EDS. Asumimos, desde este punto de vista, que tras la «lógica» de la historia se encuentran implícitos conflictos de naturaleza ideológica y luchas de intereses por ganar y legitimar posiciones de poder dentro del campo (ecologismo vs. ambientalismo); o de los campos superpuestos, que representan lo educativo y lo ambiental e, incluso en el sentido más amplio de ambos términos, lo pedagógico y lo social.

Ensayando esta combinación entre el análisis sociohistórico del campo y el microanálisis del discurso de la EA esperamos demostrar una hipótesis implícita: tras la armonía de la «lógica histórica» establecida, que parece presidir las casi cuatro décadas de su «historia», se descubre un cúmulo de ambigüedades, bucles temporales, inconsistencias, rupturas, discontinuidades y contradicciones ocultas -incluso, interesadamente ocultas- tras lo manifiesto y la aparente lógica de la flecha del tiempo. Tras estas discontinuidades se encuentra, entre otros conflictos, la pugna entre ecologismo y ambientalismo, con su traslación a la orientación de las políticas educativas posibles y deseadas ante el alcance de la crisis socioambiental.

\section{Desde 1977 a la actualidad: cuatro décadas para una trayectoria inacabada en el quehacer educativo-ambiental}

La identificación del substrato teórico y analítico que brindan Pierre Bourdieu y Michel Foucault lleva directamente a la necesidad de abordar una segunda cuestión: ¿Con qué estructura narrativa se puede revisar desde «otros puntos de vista» la trayectoria de la EA para ir más allá de lo lógico, lo re-conocido y lo instituido? ¿Es posible cambiar la mirada sobre las convergencias -inconclusas- de la EA con los movimientos ecologistas, postecologistas y ambientales?

${ }^{48}$ Bourdieu, P.: Cosas dichas, p. 62. 
DEL ECOLOGISMO COMO MOVIMIENTO SOCIAL A LA EDUCACIÓN AMBIENTAL COMO CONSTRUCCIÓN HISTÓRICA

JOSÉ ANTONIO CARIDE Y PABLO ÁNGEL MEIRA

Como venimos advirtiendo, intuimos una posible estrategia narrativa. No obedece -o quizás sí, situándola en un contexto de ciencia postnormal- a los estándares académicos, que suelen asociarse con el formalismo cartesiano de una línea argumental que organiza lógicamente un discurso, para extraer posteriormente conclusiones relevantes para la comprensión de un problema, un campo o un ámbito del saber, en este caso, de la EA. No es tanto, diremos, el relato de una construcción planificada y desarrollada conforme a un canon, sino más bien una narrativa de avances y retrocesos sucesivos, en los que el estancamiento e, incluso, la pérdida de los referentes del lugar común que constituyen el pensamiento y la acción educativo-ambiental parece mucho más un acto intencional que un acontecimiento imprevisto. Regresar a Tbilisi, del 6 al I2 de septiembre de 2012 (asociando la EA con el Ds), para celebrar 35 años después una Conferencia Internacional conmemorativa de la realizada en 1977 , no deja de ser «otra vuelta de tuerca»; un título con el que Henry James incorporó a la literatura universal la que suele considerarse como una historia de fantasmas por antonomasia, en la que intervienen presencias y personajes tal vez sobrenaturales, en un inquietante crescendo. Intentaremos explicarnos situando la trama en la EA y los movimientos sociales relacionados, desde las últimas décadas del pasado siglo hasta la actualidad.

Desde un punto de vista metafórico y simbólico, Tbilisi (1977 y +35) opera como un «mito fundacional», que algunos también han querido contemplar como el «hito del origen»: un acontecimiento histórico trascendente en el que comienza a escribirse la crónica del alumbramiento institucional y social de la Educación Ambiental. Un mito-hito que proyecta su sombra hacia cualquier futuro, incluso aunque ya no se utilice, no se conozca y/o asuma completamente el discurso que allí se formuló y el proyecto de campo que allí fue, en cierto modo, instituido. De hecho, sería un ejercicio interesante preguntar a las generaciones de educadores y educadoras que se han incorporado en las últimas dos décadas a la EA qué idea tienen de lo acontecido en Tbilisi, de su significación histórica y de su impronta en el presente, aunque podríamos encontrar que no tienen ninguna.

Lo cierto es que, ante el poder instituyente y simbólico de esta convención, son bastantes los interrogantes que se pueden plantear. Los que aquí se expresan no tienen respuestas suficientemente precisas y, mucho menos, unívocas. Las preguntas, casi siempre incómodas y tentativas, contienen en ellas un desafío de amplias avenidas pedagógicas, sociales y ambientales. Exigiendo una labor sociohistórica y «arqueológica» que trasciende los límites de este texto, los expresamos a modo de interrogantes heurísticos que buscan sugerir y provocar un debate en torno a la constitución histórica del campo de la EA y a las implicaciones que dicha constitución tiene para entender su presente. Veámoslos:

- ¿Por qué asumimos la perspectiva histórica de Tbilisi+3o pero no, por ejemplo, de Tesalónica+ıo (o +ir, si nos acercamos al lema de esta Conferencia)?

- ¿Por qué, en sintonía con la cuestión anterior, se ha puesto el contador histórico de las Cumbres Ambientales a cero en Río 1992 y, por lo tanto, la 
DEL ECOLOGISMO COMO MOVIMIENTO SOCIAL A LA EDUCACIÓN AMBIENTAL COMO CONSTRUCCIÓN HISTÓRICA

JOSÉ ANTONIO CARIDE Y PABLO ÁNGEL MEIRA

Cumbre de Johannesburgo de 2002 se adjetivó de Río+io (o la de Río en 20I2, de Río+20) y no Estocolmo+30 o +40? ¿A qué intereses obedece este ajetreo histórico?

- ¿Qué sentido tiene que el contador de la Educación Ambiental siga remitiendo a Tbilisi cuando el «marco institucional de la política ambiental global» ya no se filia a Estocolmo sino a Río de Janeiro?

- ¿Qué «cualidades» otorgan a Tbilisi su aura mítica? ¿Por qué otros encuentros posteriores (o anteriores, como el Seminario de Belgrado, 1975), mismo dentro de la propia trayectoria de la ONU, como las Conferencias de Moscú (1987), Tesalónica (1997) o Ahmedabad (2007), no han logrado la misma impronta simbólica en el campo?

- ¿Por qué otros documentos, concebidos desde fuera o en paralelo al sistema de la ONU, como el Tratado sobre Educación Ambiental para las Sociedades Sostenibles y Responsabilidad Global, consensuado en el Foro Global reunido también en Río de Janeiro (1992) a la par que la cumbre oficial, no alcanzan el mismo nivel de reconocimiento «institucional» en el campo de la EA?

- ¿Quién decide qué hitos son relevantes en la institucionalización del campo de la Educación Ambiental? ¿En base a qué autoridad académica, científica, política, y a que legitimidad? ¿Quién, en fin, enciende la luz en unas zonas y la apaga en otras y, sobre todo, en función de qué intereses?

La forma en que hemos abordado la construcción histórica de la EA, mismo desde los medios científico-académicos más críticos y menos aquiescentes con el statu quo de los organismos internacionales, ha llevado a extender y a aceptar una visión extremadamente institucionalizada de su identidad. No hay manual de EA que explícita o implícitamente, con mayor o menor agudeza crítica, no recapitule y presente la historia "contemporánea» de la Educación Ambiental como una línea continua que transita de Estocolmo (1972), a Belgrado (1975), después a Tbilisi (1977), de allí a Moscú (1987), Río de Janeiro (1992), Tesalónica (1997), etc. Siempre hacia delante, siempre asumiendo que en cada paso y etapa se superan los planteamientos de la precedente.

Lo cierto es que leyendo y analizando con rigor crítico los distintos documentos, recomendaciones y declaraciones que jalonan dicho itinerario institucional, se puede llegar a la conclusión de que nada o muy poco se ha avanzado, ni en el ajuste del discurso a lo que demanda la realidad de la crisis socioambiental, ni, quizás aún menos, en la relación de ese discurso con la praxis socioeducativa y con la evolución de la misma crisis. Gran parte del distanciamiento de los novísimos movimientos ecologistas (o postecologistas) con respecto a la EA puede atribuirse a la brecha existente entre las respuestas educativas que requiere la fase actual de la crisis socioambiental y las propuestas institucionales, ligadas a una EDS como pieza funcional de una economía de mercado supuestamente verde o reverdecida.

Como sugiere la lúcida frase del silvicultor estadounidense Aldo Leopold «cuando la lógica de la historia tiene hambre de pan y le damos una piedra, 
nosotros nos vemos en la obligación de explicar en qué se parece la piedra al pan» ${ }^{49}$, más bien hemos ido a remolque de escenarios y amenazas ambientales cada vez más complejos y de comportamientos colectivos progresivamente más insostenibles, injustos y desequilibrados desde un punto de vista ecológico y social, ante los que la $\mathrm{EA}$ ha tenido escasa capacidad de respuesta, casi siempre a pequeña escala. Es bastante razonable pensar que nosotros mismos, quienes dedicamos parte de nuestro esfuerzo científico y académico a reflexionar sobre los marcos teóricos, metodológicos o estratégicos de la EA, no sepamos ya muy bien en qué se parecen las «piedras» que ofrecemos -o que se ofrecen en el marco de las distintas políticas y estrategias ambiéntales o educativas- al «pan» que el mundo necesita.

No cabe duda de que la unEsco y el PNUMA, a partir de los mandatos de Estocolmo (1972) y Tbilisi (1977), jugaron un papel clave y un liderazgo indiscutible en la construcción del campo de la EA. Pero la lógica política y burocrática que rige su funcionamiento también ha condicionado y limitado su autonomía, con bastante frecuencia tomando distancia de los movimientos ecologistas/ambientales y de los procesos de renovación educativa, contribuyendo a difuminar los contornos científico-disciplinares, pedagógicos, sociales y políticos de la EA.

Esta relación de dependencia o apropiación no se verifica en campos que se han constituido prácticamente al unísono, dando lugar a otras disciplinas «sociales» relacionadas con el ambiente. Ni la Psicología Ambiental, ni la Sociología Ambiental, por poner dos ejemplos cercanos para trazar esta analogía, han padecido en su desarrollo la misma dependencia del sistema de las Naciones Unidas. Una y otra han acotado su objeto y su programa dentro de las disciplinas matrices, la Psicología y la Sociología, sin la cobertura de la entente unESCO-PNUma, evitando convertir las declaraciones oficiales de estos organismos en la clave de su identidad y legitimidad científica, social o profesional. En esta línea, ya en el presente, ni la Psicología Ambiental ni la Sociología Ambiental están experimentando la conversión del «desarrollo sostenible» en paradigma institucional dominante como una ruptura epistemológica dentro de los campos académicos que han creado. Por ello no oiremos hablar de «Psicología del Desarrollo Sostenible» o de «Sociología del Desarrollo Sostenible», más que en relación a líneas de investigación o de reflexión científica. En la clarificadora y minuciosa reconstrucción que realiza Dunlap ${ }^{50}$ de la génesis y evolución de la sociología ambiental desde principios de la década de los setenta hasta los años noventa del siglo pasado no hay ni una sola referencia a organizaciones o programas de las Naciones Unidas, una omisión impensable en un ensayo similar sobre el origen y la trayectoria de la EA en el mismo periodo.

Desde una óptica general, la «historia institucional» de la EA adolece, al menos, de tres problemas. En primer lugar, es una historia sin sujetos o, si se quiere,

49 Leopold, A.: A Sand County Almanac. With essays on conservation from Round River, Nueva York, Ballantine Books, 1979 (I. ${ }^{a}$ ed. 1947).

so Dunlap, R. E.: «Evolución de la sociología del medio ambiente: breve historia y valoración de la experiencia estadounidense», en Redclift, M. y Woodgate, G. (coords.): Sociología del medio ambiente. Una perspectiva internacional, Madrid, McGraw Hill, 1997, pp. 3-25. 
DEL ECOLOGISMO COMO MOVIMIENTO SOCIAL A LA EDUCACIÓN AMBIENTAL COMO CONSTRUCCIÓN HISTÓRICA

JOSÉ ANTONIO CARIDE Y PABLO ÁNGEL MEIRA

con un «sujeto colectivo» anónimo, apolítico y aideológico, que parece ocultarse detrás de las distintas convenciones, conferencias y declaraciones que arrancan de Estocolmo y se han ido prolongando en las reiteradas alusiones a la Educación Ecológica, Ambiental o para el Desarrollo Sostenible, por parte de los organismos que las promueven y tutelan. Lo que en la Agenda 2I, artículo 36, aprobada en la Cumbre de la Tierra de Río 92 se decía de la educación -como algo decisivo para el desarrollo sostenible y la mejora de la capacidad de las personas para manejar las cuestiones del medio ambiente y del desarrollo- se ha trasladado recientemente al Informe de la UNEsco titulado Rethinking Education: Towards a global common good? ?5 , en el que, sin nombrar en ningún momento a la EA, se indica que al reconsiderar la finalidad de la educación como un bien común «predomina en nuestra consideración una preocupación esencial en relación con un desarrollo humano y social sostenible. Se entiende por sostenibilidad la acción responsable de los individuos y las sociedades con miras a un futuro mejor para todos, a nivel local y mundial, un futuro en el que el desarrollo socioeconómico responda a los imperativos de la justicia social y la gestión ambiental» ${ }^{52}$.

En segundo lugar, es una historia que «progresa» o, al menos, que se entiende a sí misma como "progresiva»: los enfoques de Tbilisi fueron supuestamente superados en Moscú, los de Moscú en el capítulo 36 de la Agenda 21 consensuada en Río y en Tesalónica, y ahora por la «no-ruptura» que implica la emergencia de la EDs. Tras este sobreentendido historicista hay mucho del idealismo esencialista $^{53}$ que tanto abunda en el campo educativo (y también en el ambiental), que atribuye al discurso pedagógico per se el poder normativo y prescriptivo de cambiar la realidad. Esta lectura ingenua de la relación educación-sociedad (o educación-cambio social) ignora que la «realidad social» está sometida a múltiples tensiones, contradicciones, conflictos de intereses, luchas de clase, luchas culturales y problemas de interpretación, que se expresan también, por inclusión, en la «realidad educativa». Los mitos de Sísifo y Prometeo, condenados al eterno retorno por su compromiso con la capacidad del ser humano para transformar la realidad a través del conocimiento, deberían de ser invocados más a menudo en los foros de la EA.

$\mathrm{Y}$, en tercer lugar, la tendencia a un eclecticismo teórico e ideológico que permite hacer convivir en los «discursos institucionalizados» puntos de vista, valores e ideales políticos que son radicalmente antitéticos y antagónicos, al mismo tiempo que se propone un mensaje supuestamente apolítico y aideológico y, por lo mismo, ahistórico. De hecho, la última vuelta de tuerca que ha situado al «desarrollo sostenible» como eje de la respuesta educativa a la cuestión ambiental,

¿I UNESCO: Replantear la educación ¿Hacia un bien común mundial?, París, unesco, 2015. Accesible en: http://unesdoc.unesco.org/images/o023/002326/232697s.pdf (edición en inglés: Rethinking Education: Towards a global common good?. Accesible en: http://unesdoc.unesco.org/ images/o023/002325/232555e.pdf).

${ }_{52}$ Ibidem, p. 20.

53 González-Gaudiano, E.: Centro y periferia de la Educación Ambiental. Un enfoque antiesencialista de la Educación Ambiental, México, Mundi Prensa, 1998. 
rechazando quienes la defienden cualquier connotación política o ideológica en su definición, puede ser la traslación al campo de la EA de la idea del «fin de la historia». Así cabe entender, por ejemplo, que el «desarrollo sostenible» que se promueve nunca llega a rebasar o cuestionar los márgenes acotados, cristalizados y naturalizados de la economía de mercado, tal y como se representa, una vez más, en los Objetivos de Desarrollo Sostenible establecidos por la ONU en 2015.

Quizás no sea casual que el sobrevalorado y poco original artículo de Francis Fukuyama, en el que enuncia «el fin de la historia», se publique en $1989^{54}$. Noqueado el modelo soviético, Fukuyama levanta simbólicamente el brazo victorioso del capitalismo liberal y su versión democrática, por este orden. Con el colapso del socialismo real, no solo estaríamos entrando en la fase última y definitiva de la historia humana, sino que la misma idea de historia desaparecería para dar paso al Nuevo Orden Internacional, ya posthistórico. Este texto ve la luz solo dos años después de la publicación de Nuestro Futuro Común -al que ya hemos aludido-, más conocido como Informe Brutdland, «mito» fundacional del concepto de desarrollo sostenible; y tres años antes de la cumbre ambiental de Río de Janeiro de 1992. Como ya hemos puesto de manifiesto en otros ensayosss el lenguaje institucional de la EA desde principios de los años noventa, en el ya aludido «capítulo 36» de la Agenda 2 o en los documentos doctrinales de la unEsco para la Década de la Educación para el Desarrollo Sostenible, por poner dos ejemplos, recupera ideas y conceptos ligados a la teoría desarrollista del «capital humano» y tiende a representar el ambiente fundamentalmente como una base de «recursos» para el desarrollo económico, por poner el acento en dos piezas discursivas claramente ligadas a la pedagogía funcionalista de los años sesenta y al «ambientalismo de mercado».

La ejecución sumaria de la EA dura casi tres décadas y aún no está claro que haya dejado de existir. Aquí, sin ir más lejos, estamos escribiendo de ella. Pero sí hemos de reconocer que los sujetos individuales y colectivos que la materializan en múltiples acciones y prácticas pedagógicas concretas, a todas las escalas y a lo largo y ancho del planeta, es decir, la inmensa mayoría de quienes habitan realmente el campo de la EA, han permanecido absolutamente ajenos, ignorantes o indiferentes a este proceso de desmontaje. Y ello a pesar de que, en última instancia, tal proceso condiciona las políticas ambientales y sociales, locales o globales, que enmarcan estratégicamente la respuesta educativa a la crisis socioambiental.

\section{Entre Tbilisi y Ahmedabad: arqueología de un deseo frustrado por las realidades sociales, educativas y ambientales}

Hemos hecho hasta aquí algunas afirmaciones críticas generales sobre la historia de la EA y sobre cómo se ha construido convencionalmente. Queremos

54 Funuyama, F.: «The end of history?», The Nacional Interest, I6 (1989) [versión castellana en Claves, I, abril (I990), pp. 85-96].

"Véase Caride, J. A. y Meira, P. Á.: op. cit., y Meira, P. Á.: «In Praise of Environmental Education", Policy Futures in Education, 3, 3 (2005), pp. 284-295. 
DEL ECOLOGISMO COMO MOVIMIENTO SOCIAL A LA EDUCACIÓN AMBIENTAL COMO CONSTRUCCIÓN HISTÓRICA

JOSÉ ANTONIO CARIDE Y PABLO ÁNGEL MEIRA

asumir ahora una mirada más empírica o, retomando nuestro discurso, más arqueológica sobre esta cuestión. Para ello queremos realizar una serie de «catas» en los discursos y los entornos que materializan y rodean los hitos institucionales que articulan cronológicamente la trayectoria de la EA. Hablamos de «catas» en un doble sentido: porque no podemos extendernos, por razones de espacio, en una exploración más amplia; y porque, exprimiendo la metáfora, todo proyecto arqueológico ha de comenzar por valorar, en primer lugar, la potencialidad del «yacimiento», como paso previo para poder diseñar posteriormente una «excavación» más ambiciosa. Por ahora, nos detendremos en tres «substratos»: los que contienen la Conferencia de Ahmedabad (2007); la Conferencia de Tesalónica (1997) y su vinculación con la Cumbre de Río (1992), y la misma Conferencia de Tbilisi y el contorno histórico que la contextualiza como la primera Conferencia Internacional sobre Educación Ambiental, en 1977.

Del primer substrato hay dos evidencias relativamente recientes: la primera es el discurso pronunciado por Charles Hopkins, director de la UNESCO para la Década de la Educación para el Desarrollo Sostenible, en la sesión de apertura de la IV Conferencia Internacional de Educación Ambiental celebrada en 2007 en Ahmedabad (India), que llevaba como peculiar subtítulo Tbilisi+3o. El discurso al que nos referimos lleva por título «El camino a Ahmedabad: insertando el conocimiento ambiental en nuestro ADN cultural» ${ }^{56}$. Aunque no es ni extenso ni profundo, en él se detectan varias tesis implícitas sobre la EA y su «evolución» histórica hasta su metamorfosis en EDs. La primera apunta a una lógica histórica lineal que vincula y enlaza «genéticamente» Tbilisi con Ahmedabad, el acto fundacional de la EA en la capital georgiana con el acto inaugural para instituir la EDS en la ciudad del subcontinente indio. Según esta visión, la eDs surgiría, pues, de la evolución «natural» del campo, que ha ido avanzando y superándose en distintas escalas (Moscú, Río, Tesalónica...) hasta desembocar en un epílogo lógico, la EDS, que es ya «otra cosa» (¿otro «campo»?).

Esta convención histórica adquiere mayor significado si examinamos algunos datos de la biografía de Charles Hopkins. Este profesor canadiense de la York University participó en la delegación oficial que su Gobierno envió a la Conferencia de Tbilisi hace tres décadas. Es, pues, algo más que un testigo privilegiado, es un actor de la misma historia. Más adelante también dirigió el World Congress for Education and Communication on Environment and Development (ECO-ED), celebrado en Toronto en octubre de I992, a rebufo de la Cumbre de Río celebrada ese mismo año y con la cobertura de la unEsco. Otro dato clave lo identifica como uno de los redactores del «capítulo 36» de la Agenda 2I, primer documento internacional en el que se abandona o subvierte la expresión «Educación Ambiental» para comenzar a hablar de «Educación para el Desarrollo Sostenible».

56 Véase el texto original en Hopkins, C.: «The Road to Ahmedabad: Embedding Environmental Wisdom in our Cultural DNA», en Fourth International Conference on Environmental Education, Ahmedabad, India, 26 de noviembre de 2007. Este texto fue publicado en 2009 en el Journal of Education for Sustainable Development, 3, I, pp. 4I-44. 
DEL ECOLOGISMO COMO MOVIMIENTO SOCIAL A LA EDUCACIÓN AMBIENTAL COMO CONSTRUCCIÓN HISTÓRICA

JOSÉ ANTONIO CARIDE Y PABLO ÁNGEL MEIRA

La «historia» que dibuja Hopkins de la respuesta educativa a la crisis ambiental es, claramente, una «historia institucional», aunque ello no le impida afirmar -la corrección política obliga- que «cuando interpretamos nuestra historia, la sinergia entre la ONU y las ONGS es apropiada y apreciada por la sociedad». Su valoración de los aportes de Tbilisi es ambigua y entronca con la crítica recurrente en los últimos años al sesgo conservacionista y naturalista de la EA que allí se concibió: «Pienso en el momento en que leí los documentos finales y recuerdo mi frustración con el enfoque centrado en la naturaleza de la inmensa mayoría de los delegados». Lo que queda claro, como mensaje fuerte y central de su discurso, es que se comienza a borrar el pasado de la EA para situar en el presente (y en el futuro) la EDs. No queremos pasar por alto que el sesgo naturalista o conservacionista (ambientalista) ha sido muy importante en la práctica de la EA, sobre todo en los años setenta y ochenta. El peso de la ecología y, en general, de las ciencias naturales, en la representación de la crisis ambiental explica, en gran medida, esta distorsión. Que fuera motivado por falta de reflexión o por enfoques metodológicos erróneos ya es más que discutible. Ya en Estocolmo, Belgrado o Tbilisi se insiste en la necesidad de entender el ambiente de forma multidimensional e interdisciplinar. Las razones de que estas orientaciones no se llevasen a la práctica son de carácter más estructural y necesitan una explicación sociológica e ideológica que necesariamente trasciende el propio campo de la EA. De hecho, aún hoy se podría afirmar que la política ambiental es predominantemente conservacionista o preservacionista, aunque no se deba generalizar, ya que hay un creciente número de países en los que las políticas ambientales se decantan hacia el prodesarrollismo (como ponen de relieve los enfoques del desarrollismo ecológico y las denuncias por el neoextractivismo).

Al hilo de estas observaciones, no se acaba de entender muy bien por qué es preciso insistir en la filiación de la EA y la EDs. Como es bien sabido, el Draft para la Década de la EDS, elaborado en 2004 por la UNESCO 57 , reconoce que la EA es una disciplina con entidad propia y entiende que su aportación a la EDs puede y debe de ser importante. Esta arquitectura argumentativa entra en contradicción flagrante con el discurso que traza Charles Hopkins de la historia del campo. Dicho de otro modo, el reconocimiento formal de la naturaleza disciplinar de la EA -que, por otra parte, tampoco necesitaba- es una forma, indirecta y sutil, de acotar disciplinariamente la EDs.

Esta serie de contradicciones y ambigüedades en el discurso y en el proceso de institucionalización de la EDs está provocando no poca confusión e incertidumbre en el terreno de la práctica educativa relacionada la crisis ambiental. No debemos ignorar la dificultad de los actores educativos para discriminar cuándo hacen o se hace EA o cuándo EDS. El uso indiscriminado y polisémico del concepto de «desarrollo sostenible» por parte de organismos internacionales, gobiernos, ONG, empresas y otros grupos de interés no hace más que acrecentar el desconcierto en

57 unesco: United Nations Decade of Education for Sustainable Development 2005-2014. Draft International Implementation Scheme, octubre, 2004. 
DEL ECOLOGISMO COMO MOVIMIENTO SOCIAL A LA EDUCACIÓN AMBIENTAL COMO CONSTRUCCIÓN HISTÓRICA JOSÉ ANTONIO CARIDE Y PABLO ÁNGEL MEIRA

el ámbito en el que han de contrastarse y ponerse a prueba todos los discursos: en el terreno de la acción socioeducativa.

La segunda evidencia la situamos en otro texto relacionado con la Conferencia de Ahmedabad. El autor, probablemente, más conocido y más empático para la comunidad latinoamericana por sus vínculos con la pedagogía freiriana, es Moacir Gadotti, aunque no asistió al evento (su país, Brasil, estuvo representado por Marcos Sorrentino y Rachel Trajber). Su relato es una crónica menos institucional del evento y, quizás por ello, más sensible a los conflictos que acabamos de poner de manifiesto. Pero en su brevedad no puede obviar, y quizás de forma más acusada, algunas de las contradicciones e inconsistencias que acabamos de señalar. También contiene una reflexión histórica sobre la EA que adopta una estructura cronológica lineal, comenzando en Tbilisi y finalizando en Ahmedabad. Su título, de entrada, sorprende: Abmedabad. The encounter of environmental education with education for sustainability ${ }^{8}$.

Sorprende, en primer lugar, por la «desaparición» u «omisión» del concepto «desarrollo» ligado al de sostenibilidad. No se nos escapa el distinto significado ideológico y político que segrega la idea de sostenibilidad (considerada, por ejemplo, como un valor o principio ético universal de nueva generación), evitando su fusión y, en cierto modo, también su mixtificación cuando se incorpora al concepto «desarrollo sostenible». De hecho, el título puede resultar equívoco, dado que el eje central de la Conferencia de Ahmedabad fue la EDS -como enuncia el discurso de Hopkins- y no la Educación para la Sostenibilidad, ni, por supuesto, la sostenibilidad; cabe recordar que el eje central de la Conferencia era la Educación Ambiental, suscitándose el conflicto cuando durante la clausura ya no se mencionó el concepto.

En segundo lugar, sorprende también la calificación de «encuentro», un recurso retórico utilizado, quizás, para situar en un mismo plano jerárquico a la EA frente a la Es (o, realmente, a la EDS). Aunque en el texto se intenta justificar coherentemente la lógica de este «encuentro», lo cierto es que redunda en argumentos ya conocidos y recurre a la misma estructura del discurso institucionalizado:

Desde Tbilisi a Ahmedabad se ha producido un gran avance teórico y práctico. Las primeras preocupaciones sobre el ambiente se centraron en la preservación de la naturaleza, en su conservación. Después, el tema central fue la biodiversidad. Estos retos no fueron superados en el pasado, pero ahora, con la amenaza del calentamiento global y la crisis climática, el tema central de la EA (sic) ha de ser el estilo de vida: si no cambiamos nuestra forma de producir y reproducir nuestra existencia, nosotros pondremos en peligro todas las vidas en nuestro planeta ${ }^{\varsigma 9}$.

La lectura de Gadotti produce una sensación de déjà vu que traslada a otro «texto» clave en la historia de la Educación Ambiental: Tendencias de la Educación

${ }_{58}$ El texto completo está accesible en http://gadotti.org.br:808o/xmlui/handle/123456789/435. Otro texto de GADOTTI sobre esta cuestión, que sigue la misma línea discursiva, se puede localizar en http://gadotti.org.br:8080/jspui/bitstream/I23456789/420/2/AMG_PUB_oI_oo6.pdf.

59 Ibidem, p. I. 
Ambiental ${ }^{60}$; una obra colectiva, publicada por la UNESCO en 1977, que compila una serie de ensayos que sirvieron de base para los debates realizados en el Seminario de Belgrado (1975), antesala de Tbilisi. Al releerlos se puede comprobar, con cierta sorpresa, que casi todos han envejecido muy bien (lo que quiere decir, quizás, que estamos envejeciendo muy mal). De hecho, si se obvia el año de publicación, costaría datarlos hace más de 30 años. Veamos tres ejemplos:

Para resolver nuestros problemas ambientales debemos aprender a pensar y actuar conforme nuevas pautas ${ }^{61}$.

Cualquier sistema de subdivisión de una materia tan compleja y con tantas interrelaciones como la EA adolece de cierta arbitrariedad ${ }^{62}$.

El progreso y el desarrollo han sido ídolos de la sociedad industrial, pero ha llegado el momento de comprender que el progreso medido en función del incremento del PNB, o de las innovaciones tecnológicas, no es suficiente. Debe atribuirse un nuevo significado, más humano, a la palabra progreso ${ }^{63}$.

Ni el lenguaje ni el contenido parecen haber evolucionado demasiado. La Declaración de Abmedabad, sin ir más lejos, no hace alusión a argumentos sustancialmente distintos. Más que una línea evolutiva nos encontramos, quizás, con bucles temporales recurrentes, con avances y retrocesos que muchas veces solo implican cambios formales o semánticos, conservando un núcleo figurativo que, en lo básico, ya estaba conformado en esos primeros momentos.

\section{El «ambiente» histórico como trasfondo de la Educación Ambiental y las improntas de la sostenibilidad}

La EA que se comenzó a constituir como movimiento social y como campo disciplinar en los años setenta del siglo pasado no lo hizo sobre un discurso «ingenuamente conservacionista» o «sólo centrado en la protección de la naturaleza», tal y como se traslada desde ciertas caricaturas dibujadas desde el presente. La mirada problematizadora sobre la realidad ambiental y sobre lo que ésta «necesitaba de la educación» fue, desde un principio, más compleja, crítica e interdisciplinar, asumiendo una visión socioeconómica, ética y política que trascendía la interpretación meramente biofísica y unidimensional del ambiente o del papel de la educación ante la problemática ambiental. Los documentos de trabajo manejados en la Conferencia de Tbilisi y la misma declaración resultante son un claro reflejo de esa complejidad original.

Al respecto, resulta interesante recordar que a principios de la década de los setenta del pasado siglo ya estaban sentadas las bases teóricas, filosóficas y críticas

6o unEsco: Tendencias de la Educación Ambiental, Gembloux, UnEsco, 1977.

${ }_{61}$ Ibidem, p. 9.

${ }_{62}$ Ibidem, p. I2.

${ }_{63}$ Ibidem, p. 19. 
DEL ECOLOGISMO COMO MOVIMIENTO SOCIAL A LA EDUCACIÓN AMBIENTAL COMO CONSTRUCCIÓN HISTÓRICA JOSÉ ANTONIO CARIDE Y PABLO ÁNGEL MEIRA

para abordar y entrever la problemática ambiental desde una perspectiva compleja y multidimensional. Edgar Morin, por ejemplo, publica la primera edición de El paradigma perdido: la naturaleza bumana ${ }^{64}$ en 1973 , reclamando una «soldadura epistemológica» entre las Ciencias Sociales y las Ciencias Naturales para dar cuenta de la «unidad» y «complejidad» del mundo. El mismo año, Hans Magnus Enzensberger realiza en Para una crítica de la ecología política ${ }^{65}$ una crítica rotunda y desde la «izquierda ilustrada» a la tendencia a restringir la cuestión ambiental a campo de lo ecológico y la Ecología, denunciando el «catastrofismo» y los enfoques «tecnocráticos», y reclamando una visión más social y dialéctica de la crisis ambiental. En el terreno de la Economía también estaban sentadas las bases de una nueva racionalidad ambiental aplicada a este campo, destacando la edición, en 1971, de The entropy law and the economic process de Nicholas GeorgescuRoegen ${ }^{66}$, obra precursora de la noción de «desarrollo sostenible», que introduce la idea de un mundo cerrado y sometido a las leyes de la termodinámica-que no afectan solo a la energía, sino también a la materia-, en contradicción con la posibilidad de una expansión económica indefinida.

La Conferencia Internacional de Tesalónica. Ambiente y Sociedad: educación y Sensibilización del público para la sostenibilidad (1997) ${ }^{67}$, auspiciada por la UNESCO, es la segunda parada en esta cata exploratoria. El mandato de esta Conferencia era desarrollar estratégicamente la senda marcada en 1992 por el «capítulo 36» de la Agenda 21 y por la Declaración de Río sobre el Medio Ambiente y el Desarrollo ${ }^{68}$ (MOPT, I993). Antes de pasar a comentar el papel de evento en la trayectoria de la Educación Ambiental, nos gustaría destacar dos cuestiones al hilo de estos documentos.

Aunque es difícil saber si es una omisión intencionada y cuál sería su sentido político o ideológico, en la Declaración de Río sobre el Medio Ambiente y el Desarrollo no aparece ni una sola vez el sustantivo «educación» (ni, por supuesto, el concepto «EA»). La claridad con la que se enfatizaba en el célebre principio is de la Declaración de Estocolmo (1972) se ve aquí substituida por una redacción, la del «principio Io», que habla de «participación», del derecho de «acceso a la información ambiental» y de «sensibilización», pero no de "educación». Quizás no signifique nada, o quizás su ausencia explique la pérdida de relevancia y la marginalización, en nuestra opinión, de la «educación»-y de la EA- entre los instrumentos de respuesta a la crisis ambiental a partir de Río. De hecho, existe

${ }^{64}$ Morin, E.: Le paradigme perdu: la nature humaine, París, Éditions du Seuil, 1973. La edición en español es de 1978, con un cambio significativo en el título: El paradigma perdido, el paraíso olvidado: ensayo de bioantropología, Barcelona, Kairós.

6s Enzensberger, H. M.: Para una crítica de la ecología política, Barcelona, Anagrama, 1973.

${ }_{66}$ Georgescu-Roegen, N.: The entropy law and the economic process, Cambridge, Harvard University Press, I97I.

${ }_{67}$ UNESCO: Educación para un futuro sostenible: una visión transdisciplinaria para una acción concertada, París, unEsCO, I997.

68 El contenido del capítulo 36 de la Agenda 21 está accesible en: http://www.un.org/spanish/ esa/sustdev/agenda2i/agendazispchapter36.htm. El texto de la Declaración de Rio puede ser consultado en: http://www.un.org/spanish/esa/sustdev/agendazI/riodeclaration.htm. 
DEL ECOLOGISMO COMO MOVIMIENTO SOCIAL A LA EDUCACIÓN AMBIENTAL COMO CONSTRUCCIÓN HISTÓRICA

JOSÉ ANTONIO CARIDE Y PABLO ÁNGEL MEIRA

una tendencia cada vez más acusada a diluir lo «educativo» en las «estrategias de comunicación», de «información» o de «sensibilización», cuando se trata de distintos procesos y niveles de acción social. Acaso se pueda explicar también por la presencia muy secundaria de la perspectiva educativa en el diagnóstico y las recomendaciones contenidas en Nuestro Futuro Común ${ }^{69}$, entendida básicamente como un derecho básico que es preciso satisfacer y como palanca de progreso, sobre todo para los países «en vías de desarrollo». De hecho, las teorías del capital humano proyectan una sombra más que alargada sobre la arquitectura del informe. En él se puede leer, por ejemplo, que «el desarrollo económico y el desarrollo social pueden y deben fortalecerse mutuamente. El dinero que se emplea en la educación y la salud puede aumentar la productividad humana. El desarrollo económico puede acelerar el desarrollo social proporcionando oportunidades a los grupos desfavorecidos y difundiendo más rápidamente la educación ${ }^{7^{\circ}}$. Cada cual puede extraer sus conclusiones.

La redacción del capítulo 36 de la Agenda $2 I$ evita hacer mención expresa de la EA. De hecho, las dos únicas alusiones son históricas: para vincular la redacción del texto a los «principios fundamentales» acordados en la Conferencia Intergubernamental de Tbilisi sobre la EA de 1977 y una mención al Programa Internacional de EA, que estaba aún en vigor en aquel momento. Salvo estas menciones, el texto se refiere siempre a «la educación para el desarrollo sostenible», hasta tal punto que el primero de los tres apartados que lo estructuran lleva como título «reorientación de la educación hacia el desarrollo sostenible». Esta omisión y el enfoque escasamente crítico del capítulo 36 contrastan con la redacción y la orientación ética y políticamente comprometida del Tratado sobre Educación Ambiental para las Sociedades Sostenibles y Responsabilidad Global ${ }^{71}$, en el que la EA sigue siendo el eje del discurso. De hecho, podríamos interpretar esta discrepancia de significado y de significantes como la bifurcación y, al tiempo, visualización de una ruptura, que puede ser histórica, dentro de un campo que aún no alcanzamos a comprender del todo.

Tomando como referencia estas premisas, no diremos nada nuevo al afirmar que la Declaración de Tesalónica (1997) destaca, sobre todo, por su vaciedad y su carencia de contenido (quizás solo en competencia con la Declaración de Ahmedabab). Veamos cómo «resuelve» el boletín Contacto en 1998 algunos de los conflictos de campo que, al parecer, se escenificaron en la ciudad griega. La cita es literal:

Entre los más importantes logros de la conferencia fue el reconocimiento de que la educación no sólo es tan importante para alcanzar la sustentabilidad como

69 Comisión Mundial de Medio Ambiente y Desarrollo: Nuestro futuro común, Madrid, Alianza Editorial, 1987. La versión original en inglés del Informe está accesible en: https://web.archive.org/web/20II20I061947/http://worldinbalance.net/pdf/1987-brundtland.pdf.

70 Ibidem, p. 78.

${ }_{71}^{71}$ La traducción del Tratado al español puede consultarse en: https://www.uam.es/personal_ pdi/ciencias/jbenayas/Nueva\% 2ocarpeta/tratado_ea_espanhol.pdf. 
DEL ECOLOGISMO COMO MOVIMIENTO SOCIAL A LA EDUCACIÓN AMBIENTAL COMO CONSTRUCCIÓN HISTÓRICA

JOSÉ ANTONIO CARIDE Y PABLO ÁNGEL MEIRA

lo son la economía, la legislación, la ciencia y la tecnología, sino que además ella es un prerrequisito para todas las demás. Por otra parte, la aparente diferencia entre las dos tendencias en boga, si no son "escuelas» de pensamiento, que plantean que la Educación Ambiental y la educación para la sustentabilidad son temas diferentes fue resuelta en gran forma. Estas tendencias que derivaron, eventualmente, de diferentes puntos de vista filosóficos, deberían unirse bajo una sola denominación «Educación para el Medioambiente y la Sustentabilidad», dado que el contenido de sus mensajes es, en efecto, el mismo, y sus enfoques son más bien complementarios que antagónicos ${ }^{72}$ (cursiva nuestra).

Es difícil saber en qué bases se asentó el acuerdo, pero lo cierto es que en Tesalónica se buscó una «marca» de consenso -la «Educación para el Medioambiente y la Sostenibilidad» (a propuesta de John Smyth y que la UNESCO no respetó)-73 en un intento por resolver la ruptura que algunos sectores del campo de la EA ya percibían (y que habían presentado también durante el segundo Congreso Iberoamericano de Educación Ambiental, celebrado seis meses antes), sobre todo en relación con las implicaciones ideológicas y socioeconómicas de la concepción del desarrollo sostenible de corte claramente ambientalista y desarrollista que se estaba imponiendo en el seno de las organizaciones internacionales. De hecho, el documento preparatorio de la Conferencia de Tesalónica (1997) trata de evitar un pronunciamiento claro, utilizando más los conceptos de «sostenibilidad», de «educación y sensibilización para la sostenibilidad» o de «cultura de la sostenibilidad», en un probable intento de desmarcarse de las objeciones ideológicas a su fusión con el concepto de «desarrollo». Caber recordar que en la doctrina sobre el «desarrollo sostenible» que se institucionaliza en la Cumbre de Río de Janeiro, en 1992, no se cuestiona el dogma moderno del crecimiento económico como base de todo progreso, sino que se demanda que sea «sostenible» y matizadamente más «justo».

Es una ironía de la historia que los primeros pasos en el movimiento de institucionalización de la EA en los años 70 y 80 tuvieran como escenarios de celebración ciudades y países centrales en el proceso de desmoronamiento de la antigua Unión Soviética y del orden internacional de la Guerra Fría: Belgrado era en I975 capital de una Yugoslavia unida y Tbilisi era en I977 capital de una república socialista, en la que naciera Stalin, subsumida en la Unión Soviética. A esta lista se puede incorporar Moscú, sede del Congreso Mundial sobre Educación y Formación Ambiental en 1987, un año después del desastre nuclear de Chernóbil y en plena Perestroika, a solo dos años vista del colapso soviético simbolizado por la caída del Muro de Berlín en 1989. Si estas coincidencias tienen o responden alguna

72 Publicado en varios idiomas, el boletín Contacto fue el principal medio de difusión hasta finales de los años 9o del Programa Internacional de Educación Ambiental, impulsado por el PNUMA y la unEsCO a partir de la Conferencia de Tbilisi en I977. En este caso es el n. ${ }^{\circ}$ I de I998, p. 3.

73 Véase Harvey, T. E. y Sмyтh, J. C.: «Education 2I: An international programme for sustainable development education", en Conference on Environment and Society: Education and Public Awareness for Sustainability, Thessaloniki, December 1997, on behalf of UNED-Uk Education Task Group, 1998. 
lógica histórica habría que convenir, con cierta ironía, que la EA actuó, metafóricamente, como el caballo de Atila.

Para entender el contexto de la Conferencia de Tbilisi de 1977 y buscar en su legado las cualidades que la han convertido en nuestro particular «mito del origen» puede ser interesante trazar tres pinceladas sobre el «ambiente histórico» en el que se celebró, al que no son ajenas las dinámicas que afectan -de un modo u otro- al movimiento ecologista y/o ambientalista. Veamos:

- El antecedente inmediato de Tbilisi fue la Conferencia de las Naciones Unidas sobre el Medio Ambiente Humano celebrada en Estocolmo en 1972, la primera cumbre impulsada desde la ONU para articular una respuesta internacional a las amenazas ambientales que comenzaban a formar un escenario de crisis trasnacional más allá de sus manifestaciones locales o regionales. Como ya se ha destacado, el principio in de la Declaración de Estocolmo pone énfasis en el papel de la educación para cambiar los patrones de desarrollo y preservar el medio ambiente. De las recomendaciones emanadas de Estocolmo se derivaron, entre otros, la creación del PNUMA y el encargo a la UNESCO de articular internacionalmente las respuestas educativas a las amenazas ambientales. Tbilisi, de alguna forma, ya estaba en marcha. Estocolmo escenificó la disyuntiva entre «desarrollo» o «preservación ambiental», sobre todo, por el temor fundado entre los países del Tercer Mundo a que el argumento preservacionista fuese utilizado para coartar sus legítimas aspiraciones de desarrollo. La Cumbre de Estocolmo fue también, como Tbilisi, una reunión «gubernamental», a nivel de Estados y para actuar a este nivel político, con lo que esto significaba en un escenario de Guerra Fría, con muchos países aún en proceso de descolonización o luchando por conseguirla, y cuando la deuda externa de los países subdesarrollados comenzaba a pesar como una losa en sus posibilidades de desarrollo.

- En 1977, Carter fue nombrado presidente de los Estados Unidos, imprimiendo a su mandato cierta sensibilidad hacia los problemas del Tercer Mundo, los derechos humanos y el ambiente. De la importancia de su labor para el asentamiento de una «política ambiental internacional» a finales de los años setenta da cuenta la exhortación que hace a sus compatriotas en su discurso de despedida, destacando «la necesidad de seguir luchando por la protección de los derechos humanos en el mundo, las negociaciones para la limitación de la carrera de armamentos nucleares, la protección del ambiente y la adaptación del sistema de vida norteamericano a la crisis energética» ${ }^{74}$. Su álter ego en la Unión Soviética era en 1977 Leonid Brézhnev, que comenzaba su segundo mandato como presidente del Presidium del Soviet Supremo (1977-1982). Brézhnev no estuvo en Tbilisi, pero sí envió una carta para que fuera leída en la inauguración de la Conferencia. En ella, el jerarca soviético afirmaba, por ejemplo, que en la Unión Soviética

74 El País, Is de enero de i98I. 
DEL ECOLOGISMO COMO MOVIMIENTO SOCIAL A LA EDUCACIÓN AMBIENTAL COMO CONSTRUCCIÓN HISTÓRICA

JOSÉ ANTONIO CARIDE Y PABLO ÁNGEL MEIRA

«la protección de la naturaleza y la mejora del ambiente son consideradas como las tareas más importantes de la economía nacional»75; una retórica hueca que quedaría radicalmente desmentida al desmoronarse la Unión Soviética una década más tarde.

- La tercera pincelada tiene que ver, propiamente, con el «ambiente» en la EA de la época. Merece fijar la atención, principalmente, en las coincidencias que existen en los análisis que hacen de esta etapa dos autores de distinta adscripción geográfico-cultural y que examinan la génesis del campo de la EA: en la realidad latinoamericana, González-Gaudiano ${ }^{76}$; y, en la anglosajona, Annette Gough ${ }^{77}$. Como uno y otra destacan, ya en los años setenta eran las concepciones occidentales, predominantemente anglosajonas, las que ejercían su hegemonía en la construcción del discurso de la EA. Se produce una pugna simbólica, con tintes escolásticos, por reivindicar la fundación del campo y por acuñar una definición que acotase su objeto disciplinar, además de por establecer sus principios y objetivos. La EA aparece, entonces, esencialmente ligada a las reflexiones sobre la reforma de la educación escolar y, más en particular, del currículo oficial. Mientras tanto, otros ámbitos educativos - mal llamados «no formales»- tendrán una presencia marginal, aunque el peso de la Educación Popular en Latinoamérica, de los movimientos alternativos y los conflictos asociados con el subdesarrollo del Tercer Mundo incorporan otros contextos y procesos socioeducativos.

El papel hegemónico que juega la Ecología como ciencia de referencia en la construcción de la cuestión ambiental en los años sesenta y setenta, hasta su manifestación como Ecología Política, se expresa también en el campo educativo. El solapamiento entre la Educación Ambiental, la Didáctica de las Ciencias Naturales y la «alfabetización ecológica» era frecuente, tanto en los conceptos e ideas que se utilizan, como en la adscripción disciplinar y científica de quienes las producen. La identificación entre EA y la enseñanza de la Biología era común. Como sucedió también en los inicios de este campo en España, la EA surgió más ligada al campo de la Ecología y de las Ciencias Naturales, en general, que al de las Ciencias de la Educación. Este origen introduce una fractura epistemológica que, de alguna forma, aún se mantiene. Gran parte de la inestabilidad que caracteriza históricamente el campo de la Educación Ambiental tiene sus raíces en esta «doble adscripción» o «doble cultura», mucho más marcada hace 30 años. El peso de la Ecología, que llevó incluso a concretar sus aportes en la llamada «Educación Ecológica», insufló en el incipiente campo de la EA la legitimidad científica de

75 Unesco: Intergovernmental Conference on Environmental Education. Final Report, París, UNESCO, 1978, p. 58.

${ }^{6}$ GonzÁlez-Gaudiano, E.: Educación Ambiental: historia y conceptos a veinte años de Tbilisi, México, Sistemas Técnicos de Edición-sitesA, 1997.

77 Gough, A.: Education and the Environment - Policy, Trends and the Problems of Marginalization, Melbourne, The Australian Council for Educational Research, 1997. 
una «ciencia natural» que se regía por el método científico, incorporando un halo positivista que la Pedagogía u otras Ciencias de la Educación no podían aportar. Otro denominador común era la confianza prometeica puesta en la EA para liderar una reforma integral del currículo y para transformar las relaciones entre el sistema educativo, las instituciones escolares y la sociedad.

La Conferencia Intergubernamental de Tbilisi fue un producto histórico de su época, pero el discurso allí institucionalizado, desde el diagnóstico de la crisis ambiental, hasta los objetivos y principios estratégicos definidos para la EA, pasando por las bases epistémicas, socioeconómicas y éticas formuladas, mantiene una actualidad sorprendente y paradójica. Constituye una referencia más sólida, sin duda, para la construcción de la EA como un campo autónomo, ideológicamente plural, democrático y epistemológicamente sólido, que los subproductos discursivos resultantes de los foros posteriores (Moscú, Tesalónica, Ahmedabad, etc.). Esto es, los habitantes del campo de la EA, al menos los que siguen habitando este campo, muestran -mostramos- una fina intuición al seguir encomendando nuestra identidad a Tbilisi; al igual que el proyecto de bifurcación y desdoblamiento del campo que se ha dado en llamar EDS, que "pretende ser universal e imponerse de manera hegemónica» ${ }^{78}$, sigue convocándonos y convocándose (en Ahmedabad) bajo la misma advocación. Tbilisi, como todo «mito fundacional», posee un capital simbólico apetecible y apetecido al que ni siquiera quieren renunciar quienes declaran que la EA está ya acabada.

Además, lo que resumimos como «Tbilisi» encierra significados que deben desvelarse y revalorizarse para entender la historia del campo de la Educación Ambiental. El flashback realizado en este ensayo demuestra hasta qué punto seguimos redundando en enfoques, lenguajes y discursos ya formulados en los años setenta y ochenta, aunque no sepamos muy bien quiénes los idearon y en función de qué intereses operaban, por ejemplo, en las negociaciones que acordaron en Tbilisi la estrategia seminal de la EA. La UNESCO y el PNUMA aparecen como actores institucionales legitimados (o autolegitimados) para establecer de facto las reglas del juego, regular el timing histórico de los cambios y definir qué actores -individuales o colectivos- son centrales o periféricos en el campo de la EA. $\mathrm{Su}$ autonomía e identidad están muy condicionadas y lastradas por esta distorsión, históricamente constituida y corporativamente aceptada, salvo excepciones, como parte de una línea de evolución natural cuya última convención es la EDs.

Afirmábamos en algún momento que la EA es un campo científico, pedagógico y «social» improbable. Lo decimos poniendo de relieve que son muchas las rupturas y los conflictos larvados que, de forma continuada, han movido y alterado los límites de «su» campo. Quizás la polémica «no expresa» generada por la emergencia hegemónica de la EDs sirve para poner en evidencia las relaciones de poder y marginalidad estructural de lo educativo dentro (o, realmente, «al»o «en el» margen) del campo ambiental; $y$, en buena medida, también de su presencia activa en los movimientos ecologistas y ambientales.

78 Sauvé, L.: «Prefacio» a GonZÁlez-Gaudiano, E.: Educación Ambiental: trayectorias, rasgos y escenarios, México, Plaza y Valdés, 2007, pp. 13-22 (c. p. I8). 
DEL ECOLOGISMO COMO MOVIMIENTO SOCIAL A LA EDUCACIÓN AMBIENTAL COMO CONSTRUCCIÓN HISTÓRICA

JOSÉ ANTONIO CARIDE Y PABLO ÁNGEL MEIRA

Aunque Bourdieu nunca utilizó la expresión «trans-campo»-pero sí la de «sub-campo»-79, tendemos a pensar la EA como una forma de ejemplificarlo: un espacio educativo y social movedizo, de límites imprecisos, de poca consistencia científica y dependiente en demasía de «externalidades» e intereses espurios que, lejos de enriquecer su desarrollo, actúan como un lastre que endurece el camino. Como «trans-campo», sus propiedades son imprecisas e inestables, y fluctúan generando un terreno de nadie, intersticial, entre los campos «ambiental» y «educativo», que se estructuran y comportan en función de lógicas sociales más fuertes. Esta indefinición explica, por ejemplo, el nomadismo de los educadores y las educadoras ambientales, la dificultad para perfilar nichos académicos o profesionales específicos, y el déficit mismo de institucionalización que padece la Educación Ambiental, dado el escaso rango que se le concede en el marco de las instituciones y las distintas escalas de las Administraciones públicas ${ }^{80}$. Desde este punto de vista, la situación no ha evolucionado demasiado desde Tbilisi, aunque el «movimiento de la $\mathrm{EA} »^{81}$ sea ahora más amplio y sus productos, agentes y acciones se hayan multiplicado exponencialmente desde los años setenta del pasado siglo.

\section{Buscando un epílogo: la Educación Ambiental y los movimientos sociales en los trayectos del nuevo milenio}

Una de las características del campo -o trans-campo- de la EA es, precisamente, la experiencia militante de sus agentes como actores de movimientos sociales, tanto en el terreno de los colectivos ecologistas o ambientalistas, como en el terreno de los movimientos educativos -los MRP, en el caso de España-, políticos -preferentemente afines a la izquierda ideológica- o culturales ${ }^{82}$. La crisis de estos movimientos, tanto de los que fueron calificados como Nuevos Movimientos Sociales en las décadas de los 80 y 90 del siglo pasado, como de los viejos movimientos sociales, organizados en forma de partidos o sindicatos, coincide y, posiblemente, es atribuible a los factores coyunturales o estructurales que también están en la génesis de la crisis de identidad de la EA en el momento actual ${ }^{83}$.

Entre los factores coyunturales cobra especial relevancia la crisis económica que ha azotado la economía mundial durante el último decenio; una crisis que

79 Bourdieu, P. y Wacquant, L. J. D.: Respuestas. Por una Antropología reflexiva, México, Grijalbo, 1995, pp. 63-69.

so Sobre los problemas que genera la dependencia institucional del campo de la EA para quienes se mueven en él puede verse Howell, R. A. y Allen, S.: «Significant life experiences, motivations and values of climate change educators», Environmental Education Research, doi: IO.IO80/13504622.20I6.II58242, 20I6; y Barba, M.; Morán, M. C. y MeIra, P. Á.: «A educación ambiental en Galicia: controversias sobre o desenvolvemento do campo e o seu estado actual», Ambientalmente Sustentable, 20 (2015), pp. 33-48.

8i Calvo, S. y Gutiérrez, J.: op. cit.

82 Barba, M.; Morán, M. C. y Meira, P. Á.: «La educación ambiental en tiempos de crisis».

${ }_{83}$ Véase Meira, P. Á.: «Outra lectura da historia da Educación Ambiental», y BARBA, M.; MoRÁn, M. C. y MeIra, P. Á.: «A educación ambiental en Galicia». 
ha servido para relegar a un segundo plano las políticas públicas ambientales $\mathrm{y}$, dentro de ellas, las políticas de EA. Entre los factores estructurales cabe destacar la dificultad del ecologismo para concretar su proyecto político-social, ante la hegemonía de la economía global de mercado. Esta impotencia se ha agudizado en las últimas dos décadas al hacerse hegemónico, al menos en el lenguaje institucional y del mercado, el paradigma reformista del «desarrollo sostenible». Las controversias entre la EA y la EDS reflejan esta crisis en el campo educativo.

El autoanálisis al que se aplica el propio movimiento ecologista sobre la posibilidad de transformar el statu quo de la economía global de mercado da frutos cada vez más pesimistas. A pesar de los esfuerzos realizados por el ecologismo y el ambientalismo desde los años setenta del siglo pasado, la evaluación científica de la biosfera muestra que estamos lejos de la sostenibilidad ambiental y que, en muchos aspectos, la situación ha empeorado. La crisis ambiental no es una simple disfunción del modelo, sino una profunda crisis estructural de uno de sus principios centrales: el crecimiento como premisa del desarrollo. Como sintetizan Howes et al.,

si bien se han producido mejoras parciales en indicadores puntuales para algunos lugares, el empeoramiento de la calidad ambiental no ha remitido y ningún país ha logrado la sostenibilidad ambiental. La huella ecológica mundial (que mide el uso de recursos) superó la capacidad sostenible del planeta en 1970 y ha seguido aumentando, mientras que el índice de biodiversidad ha disminuido en más de la mitad. Las emisiones de gases de efecto invernadero están aumentando y los impactos del calentamiento global están creciendo, mientras que los costos de ambos impactos y las políticas de mitigación enfrentan problemas de equidad ${ }^{84}$.

Abundan los científicos, políticos y educadores que piensan que el tiempo se está acabando para la forma actual de civilización humana, a punto de chocar con los límites biofísicos de un planeta incapaz de suministrar los recursos necesarios para mantener los ritmos actuales de producción y consumo y de absorber los detritus de la acción antrópica. Para Orr ${ }^{85}$, el cambio climático y la extinción masiva de especies son el autorretrato más certero de la crisis de la civilización industrial. Es este escenario de "colisión contra los límites», advierte Orr, el que debería motivar, en una especie supuestamente racional, la reconsideración de suposiciones, paradigmas, leyes, regulaciones y, no menos importante, de las formas de educar para actuar en consecuencia. Helen Kopnina ${ }^{86}$ dibuja, en la misma línea, tres escenarios de futuro a medio plazo para las respuestas educativas a la crisis ambiental: la senda del desarrollo sostenible y la «modernización ecológica»

${ }_{4}$ Howes, M.; Wortley, L.; Рotts, R.; Dedekorkut-Howes, A.; Serrao-Neumann, S.; Davidson, J.; Sмith, T. y Nunn, P.: «Environmental Sustainability: A Case of Policy Implementation Failure?», Sustainability, 9, 165 (2017); doi: 10.3390/su9020165.

85 Orr, D.: «Foreword», en Jickling, B. y STERling, S. (eds.): Post-sustainability and environmental education, Londres, Palgrave-Macmillan, 20I7, pp. viI-XI.

86 Kopnina, H.: «Future scenarios and Environmental Education», The Journal of Environmental Education, 45, 4 (2014), pp. 217-231. 
DEL ECOLOGISMO COMO MOVIMIENTO SOCIAL A LA EDUCACIÓN AMBIENTAL COMO CONSTRUCCIÓN HISTÓRICA JOSÉ ANTONIO CARIDE Y PABLO ÁNGEL MEIRA

del capitalismo, fundada sobre el paradigma del Desarrollo Sostenible; la del reconocimiento de los límites biofísicos del planeta y la posibilidad del colapso socioambiental; y la de una nueva era del Antropoceno en la que la humanidad asuma su ecodependencia de la naturaleza y actúe en consecuencia. El tercer escenario es, para nosotros, el más deseable, pero el segundo es, a la vista de lo que la ciencia enseña, el más probable.

Esta situación de «crisis de la crisis» socioecológica explica en buena parte los conflictos de identidad en el campo de la EA, que parten del cuestionamiento de su capacidad para contribuir a la transformación socioeconómica necesaria para eludir un posible colapso. Por una parte, se consolida en el terreno de la institucionalización la apuesta por la EDS, sacralizada ahora por el sistema de las Naciones Unidas en la definición de los Objetivos de Desarrollo Sostenible (2015); una EDS que se pone al servicio de un «crecimiento verde» o «sostenible», para modernizar desde un punto de vista ecológico un modelo económico y de desarrollo al que no se puede renunciar para que cumpla su misión prometeica de crear riqueza y, supuestamente, bienestar para toda la humanidad.

Tal es así que, en la concepción de los Objetivos de Desarrollo Sostenible (oDs), los «objetivos ambientales» tienen un peso importante; pero el crecimiento económico sigue priorizándose como clave para el desarrollo humano: la misma denominación del Objetivo 8 establece el imperativo de «promover el crecimiento económico sostenido», que no sostenible, para establecer como meta «mantener el crecimiento económico per cápita de conformidad con las circunstancias nacionales y, en particular, un crecimiento del producto interno bruto de al menos el $7 \%$ anual en los países menos adelantados», una tasa mayor que la propuesta en 1987 por el Informe Brundtland.

El dogma capitalista del crecimiento sigue, pues, intocable y la educación se pone a su servicio: el objetivo 4 de los oDs, sobre la necesidad de promover una educación de calidad, establece como una meta para 2030 «asegurar que todos los alumnos adquieran los conocimientos teóricos y prácticos necesarios para promover el desarrollo sostenible, entre otras cosas mediante la educación para el desarrollo sostenible y los estilos de vida sostenibles, los derechos humanos, la igualdad de género, la promoción de una cultura de paz y no violencia, la ciudadanía mundial y la valoración de la diversidad cultural y la contribución de la cultura al desarrollo sostenible» ${ }^{87}$ (cursiva nuestra). No hay en los oDs referencias explícitas a la necesidad de considerar los límites biofísicos del planeta o las causas estructurales, fundamentalmente económicas, que nos llevan en rumbo de colisión hacia ellos, sin que los recursos naturales y las cargas resultantes de su transformación se distribuyan equitativamente. Es, desde el punto de vista de la EA, redundar en la bifurcación que se estableció en el capítulo 36 de la Agenda $2 I$ aprobada en Río 1992.

La visión pesimista de la crisis socioambiental y la ineficacia de las políticas institucionales adoptadas, bien ejemplificada por la deriva de la política climática

${ }^{87}$ Los Objetivos de Desarrollo Sostenible y las metas asociadas a cada uno pueden consultarse en: http://www.un.org/sustainabledevelopment/es/objetivos-de-desarrollo-sostenible/. 
global, ha llevado al movimiento ecologista surgido en el último cuarto del siglo $\mathrm{xX}$ a cuestionar su capacidad para mudar el sistema desde dentro. Es posible hablar de una era postecologista ${ }^{88}$. Por una parte, el capitalismo global de mercado ha integrado la perspectiva del desarrollo sostenible, con un discurso ambientalista, de modernización ecológica, inocuo para sus intereses dado que no se cuestiona el crecimiento. La confianza en el progreso tecnocientífico, en la supuesta desmaterialización de la economía y en la posibilidad de desacoplar el crecimiento y el desarrollo -medidos en puntos de PIB, renta per cápita o IDH- de la degradación ambiental son argumentos recurrentes de un capitalismo globalizado que aspira a ser verde sin renunciar a su esencia productivista.

Por otra parte, en la última década están emergiendo novísimos movimientos sociales, herederos de la cultura ética y política del ecologismo primigenio, pero caracterizados por un escepticismo notable sobre la posibilidad de alterar la trayectoria de la civilización contemporánea sin romper drásticamente con los dogmas, esencialmente económicos, en los que se fundamenta. De hecho, la mayor parte de estos colectivos apuestan por el colapso inminente, si no se está produciendo ya, de la civilización humana actual.

\section{A modo de conclusión}

No fue el ecologismo un movimiento homogéneo en sus orígenes y tampoco lo es ahora. Bajo la etiqueta de este postecologismo del colapso se agrupan movimientos y colectivos como el decrecentista, la permacultura, las comunidades en transición, las ecoaldeas o ecocomunidades de inspiración ecosocialista o libertaria, etc. A estos movimientos, impulsados fundamentalmente desde Occidente, cabe sumar los movimientos de justicia ambiental, que han tomado impulso en las periferias del sistema y que tienen como fin principal defender la integridad ecológica y cultural de los territorios que aún usufructúan los pueblos indígenas en una corriente social que Martínez Alier ya calificó en los años 90 como «ecologismo de los pobres» $\mathrm{O}$ 《ecologismo popular» ${ }^{89}$.

Un denominador común de esta constelación de novísimos colectivos es la asunción del colapso inevitable de la civilización humana tal y como la conocemos.

88 El concepto de postecologismo ha sido propuesto, entre otros, por BLÜHDORN, I.: Post-Ecologist Politics: Social Theory and the Abdication of the Ecologist Paradigm, Londres, Routledge, 20I5; y BlüHdorn, I. y Whels, I.: The politics of unsustainability. Eco-politics in a post-ecologist era, Nueva York, Routledge, 2008.

89 Martínez-Alier, J.: De la economía ecológica al ecologismo popular, Barcelona, Icaria, 1992. Las tesis de esta obra han sido actualizadas en Martínez-Alier, J.: El ecologismo de los pobres: conflictos ambientales y lenguajes de valoración, Barcelona, Icaria, 2oII. En el contexto latinoamericano merecen consultarse, entre otras, las contribuciones de PoRTO-GonçAlves, C. W.: Territorialidades y lucha por el territorio en América Latina. Geografía de los movimientos sociales en América Latina, Caracas, Editorial Ivic, 2009; y Svampa, M.: «Protesta, movimientos sociales y dimensiones de la acción colectiva en América Latina», texto presentado en las Jornadas de Homenaje a C. Tilly, Madrid, Universidad Complutense de Madrid-Fundación Carolina, mayo de 2009. Accesible en: http://maristellasvampa.net/archivos/ensayo57.pdf. 
DEL ECOLOGISMO COMO MOVIMIENTO SOCIAL A LA EDUCACIÓN AMBIENTAL COMO CONSTRUCCIÓN HISTÓRICA

JOSÉ ANTONIO CARIDE Y PABLO ÁNGEL MEIRA

Un colapso desencadenado por su incapacidad para operar dentro de los límites biofísicos del planeta y por los crecientes conflictos entre sociedades y dentro de cada sociedad, motivados por la paulatina escasez de recursos (alimentos, energía, metales, agua, etc.), insuficientes para satisfacer adecuadamente las necesidades de una población en progresión exponencial, tanto en el número de personas como en la cantidad de recursos que consumen y en los desechos que emiten. El cambio climático, la pérdida de biodiversidad y el agotamiento de las fuentes fósiles de energía son los jinetes del Apocalipsis que estos movimientos suelen señalar como evidencias del colapso inminente.

La EA no es una preocupación central para el novísimo ecologismo. En cierta medida es un espacio social ajeno y desconocido. En gran medida porque es un campo que genera desconfianza, la que se atribuye al sistema educativo y, por extensión, a todas las formas sistemáticas de educar en la sociedad, como una institución clave para la reproducción y la legitimación cultural de la hegemonía del modelo socioeconómico dominante. De hecho, la situación de emergencia socioecológica hace necesario comenzar a construir la praxis de una EA para la Sostenibilidad o para la Cultura de la Sostenibilidad que ponga en cuestión el actual modelo de producción y consumo y, por lo tanto, la línea institucionalizada de la EDS. Una EA que incorpore en su discurso y sus prácticas la idea de decrecimiento o, si se quiere, de un decrecimiento ambientalmente sostenible y socialmente justo, asumiendo que cualquier otra sociedad posible solo lo será si se asume, a escala local y global, que el planeta es finito y que somos, inevitablemente, una especie eco- e inter-dependiente. 
